\title{
Dynamic T cell-APC interactions sustain chronic inflammation in atherosclerosis
}

\author{
Ekaterina K. Koltsova, ${ }^{1}$ Zacarias Garcia, ${ }^{1}$ Grzegorz Chodaczek, ${ }^{1}$ \\ Michael Landau, ${ }^{2}$ Sara McArdle, ${ }^{1,3}$ Spencer R. Scott, ${ }^{2}$ Sibylle von Vietinghoff, ${ }^{1,4}$ \\ Elena Galkina, ${ }^{5}$ Yury I. Miller, ${ }^{6}$ Scott T. Acton, ${ }^{2}$ and Klaus Ley ${ }^{1}$
}

\begin{abstract}
1Division of Inflammation Biology, La Jolla Institute for Allergy and Immunology (LIAI), La Jolla, California, USA. ${ }^{2}$ Department of Electrical Engineering, University of Virginia, Charlottesville, Virginia, USA. ${ }^{3}$ Department of Bioengineering, UCSD, La Jolla, California, USA. ${ }^{4}$ Department of Medicine, Hannover Medical School, Hannover, Germany. ${ }^{5}$ Department of Microbiology and Molecular Cell Biology, Eastern Virginia Medical School, Norfolk, Virginia, USA. ${ }^{6}$ Department of Medicine, UCSD, La Jolla, California, USA.
\end{abstract}

\begin{abstract}
Atherosclerosis is a chronic inflammatory disease of large and medium-sized arteries characterized by leukocyte accumulation in the vessel wall. Both innate and adaptive immune responses contribute to atherogenesis, but the identity of atherosclerosis-relevant antigens and the role of antigen presentation in this disease remain poorly characterized. We developed live-cell imaging of explanted aortas to compare the behavior and role of APCs in normal and atherosclerotic mice. We found that $\mathrm{CD}^{+} \mathrm{T}$ cells were capable of interacting with fluorescently labeled (CD11c-YFP') APCs in the aortic wall in the presence, but not the absence, of cognate antigen. In atherosclerosis-prone $A$ poe $^{-/-} \mathrm{CD} 11 \mathrm{c}-\mathrm{YFP}^{+}$mice, APCs extensively interacted with $\mathrm{CD}^{+} \mathrm{T}$ cells in the aorta, leading to cell activation and proliferation as well as secretion of IFN- $\gamma$ and TNF- $\alpha$. These cytokines enhanced uptake of oxidized and minimally modified LDL by macrophages. We conclude that antigen presentation by APCs to $\mathrm{CD}^{+} \mathrm{T}$ cells in the arterial wall causes local $\mathrm{T}$ cell activation and production of proinflammatory cytokines, which promote atherosclerosis by maintaining chronic inflammation and inducing foam cell formation.
\end{abstract}

\section{Introduction}

Atherosclerosis is a complex disease associated with lipid accumulation in the vessel wall that results in the formation of atherosclerotic plaque in arteries, inflammation, progressive plaque growth, rupture, thrombosis, and occlusion of the vessel (1). Immune cells - including T lymphocytes as well as myeloid APCs, such as macrophages and DCs - are present in normal vessels and greatly expanded under atherosclerotic conditions in the arterial wall and atherosclerotic plaques (2-7). Although macrophages have long been known to be key cells in atherosclerosis $(8,9)$, the phenotype and function of macrophages and DCs in the arterial wall is poorly understood.

Being a part of the innate immune system, macrophages and DCs express pattern recognition receptors. Their activation by exogenous or endogenous ligands results in secretion of proinflammatory cytokines like TNF- $\alpha$, IL-6, or IL-12 $(3,10)$, which leads to increased local inflammation and plaque instability (11). Macrophages secrete a wide variety of proinflammatory cytokines and chemokines and are key cells for lipid retention, plaque growth, and instability (12). Lipoprotein accumulation and formation of lipid-loaded foam cells is one of the major events in the initiation and progression of atherosclerosis (6).

Since the discovery of vascular DCs (13), their role in shaping the immune response has been postulated, with recent studies beginning to address their function (14-18). In mouse models of atherosclerosis, APCs were reported to leave the vessel wall and appear in draining lymph nodes (19). In peripheral tissues, DCs typically sample antigen and return to the spleen or lymph nodes to initiate an immune response by activating naive T cells. APC interactions with $\mathrm{CD}^{+} \mathrm{T}$ lymphocytes in lymphoid organs lead to activation,

Conflict of interest: The authors have declared that no conflict of interest exists. Citation for this article: J Clin Invest. 2012;122(9):3114-3126. doi:10.1172/JCI61758. proliferation, and cytokine secretion. These interactions can be visualized by 2-photon microscopy: the $\mathrm{T}$ cells arrest their motility when they form an immunological synapse with DCs $(20,21)$. Recent intravital imaging work in models of skin inflammation (22), liver granulomas (23), and EAE, a mouse model of multiple sclerosis (24), has revealed that $\mathrm{CD} 4^{+} \mathrm{T}$ cells can be restimulated directly in peripheral tissues, proliferate, and produce cytokines.

Various types of $\mathrm{T}$ cells play different roles in atherosclerosis (25). In lymph nodes draining the aortas of Apoe $e^{-/}$mice, IFN- $\gamma-$ producing $\mathrm{CD}^{+} \mathrm{T}$ cells were found early in disease, but after 8 weeks of Western diet (WD) feeding, the $\mathrm{CD}^{+} \mathrm{T}$ cell subset became predominant (26). Moreover, a deficiency in $\mathrm{CD}^{+} \mathrm{Th}$ cells curtails atherosclerotic plaque formation and progression (27). Among $\mathrm{CD}^{+} \mathrm{T}$ cells, the Th1 subtype, which preferentially produces IFN- $\gamma$ and TNF- $\alpha$, was shown to be proatherogenic, whereas Th2 cells played only a minor role (28-30). In most studies, Th17 cells have been found to play a proatherogenic role (31-37), although some other studies came to a different conclusion (38-40). Tregs are atheroprotective, presumably due to their ability to suppress local and systemic inflammation (41-43).

While atherosclerosis-specific antigens are not yet completely characterized (44-46), recent work suggests that ApoB-reactive T cells expand during hypercholesterolemia and secrete cytokines that drive vascular inflammation (47). Depletion of antigen by vaccination against ApoB100 peptides limits atherosclerosis (47). Regardless of the relevant autoantigen, the atherosclerotic environment appears to provide both the danger signal (TLR ligands as well as oxidized and otherwise modified lipids, mainly in the LDL compartment) and $\mathrm{CD} 4^{+} \mathrm{T}$ cell antigens.

The potential role of antigen presentation by APCs to T cells in atherosclerosis progression is supported by data showing that atherosclerosis in $\mathrm{Ldll}^{-/}$mice is ameliorated when the genes encoding 2 major APC costimulatory molecules, CD80 and 
A

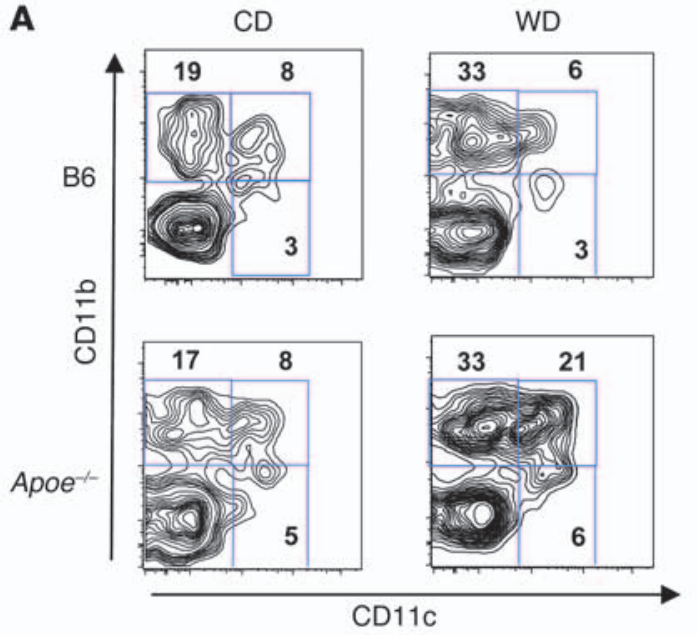

B

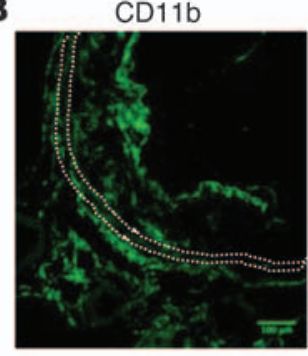

C

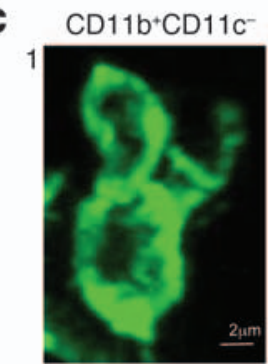

CD11C

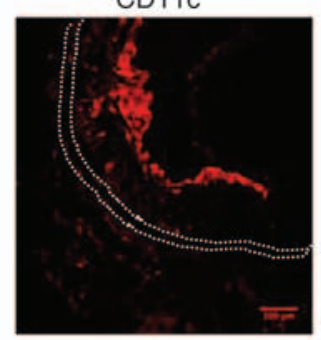

CD11b-CD11c ${ }^{+}$

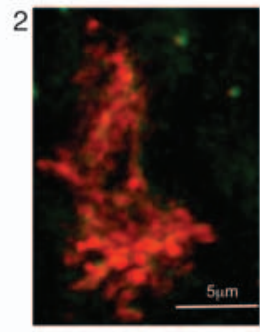

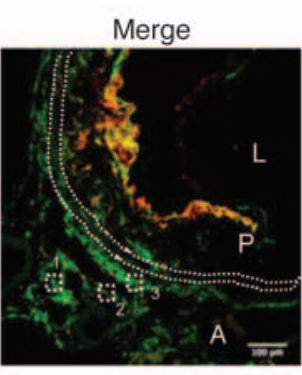

$\mathrm{CD}_{11 \mathrm{~b}+\mathrm{CD} 11 \mathrm{c}^{+}}$

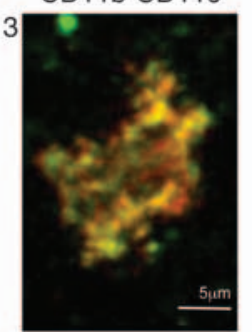

D
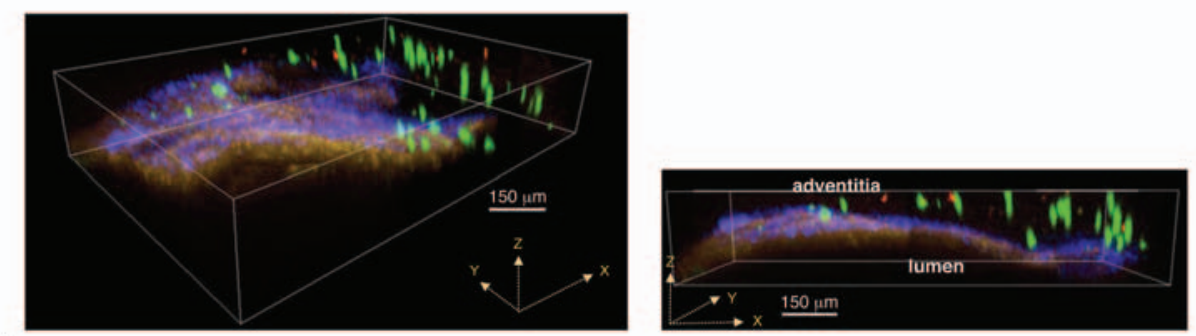

E
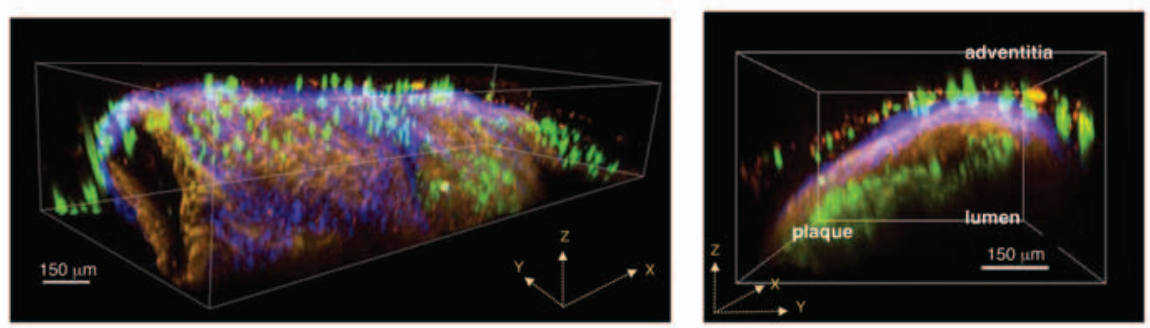

Figure 1

Myeloid cells in aortic plaque and adventitia. (A) Live CD45+ cells from aortas of Apoe-/- mice fed CD or WD for 12 weeks were stained for CD11b and CD11c. Numbers indicate percentage in each quadrant. (B) Localization of CD11 $\mathrm{b}^{+} \mathrm{CD}_{11 \mathrm{c}^{-}}$(green), CD11b+CD11 $\mathrm{c}^{+}(\mathrm{yellow})$, and $\mathrm{CD}_{11 \mathrm{~b}}-\mathrm{CD} 11 \mathrm{C}^{+}$(red) cells in aortic roots of WD-fed $A p o e^{-/-}$mice, shown by immunofluorescence. Dotted white lines indicate border of lamina muscularis. L, lumen; P, plaque; A, adventitia. Representative images from at least 3 independent experiments. (C) Examples of CD11 b+CD11 $\mathrm{C}^{-}$, $\mathrm{CD} 11 \mathrm{~b}+\mathrm{CD} 11 \mathrm{c}^{+}$, and CD11 $\mathrm{b}^{-} \mathrm{CD} 11 \mathrm{c}^{+}$cells in the adventitia enlarged from boxed regions in $\mathbf{B}$. Localization of CD11c-YFP+ cells (green) in normal B6 (D) and in atherosclerotic Apoe-/- (E) mouse aorta. Blue, second harmonic; brown, autofluorescence. Scale bars: $100 \mu \mathrm{m}$ (B); $2 \mu \mathrm{m}$ (C, left); $5 \mu \mathrm{m}$ (C, middle and right); $150 \mu \mathrm{m}$ (D and $\mathbf{E})$.

CD86, are disrupted (48). Similarly, mice lacking CD74 (MHCIIassociated protein invariant chain, which regulates antigen processing and inhibits DC motility in vivo; ref. 49) also demonstrate a marked reduction of atherosclerosis (50). However, the local activation of $\mathrm{T}$ cells in the arterial wall in atherosclerosis remains poorly understood.

Previous studies have shown DCs in close proximity to $\mathrm{T}$ cells within unstable atherosclerotic plaques $(18,51-54)$. Elegant in vitro experiments using $3 \mathrm{D}$ tissue-engineered vessels populated with in vitro-generated myeloid cells and $\mathrm{T}$ cells showed that CD11 $\mathrm{c}^{+}$APCs activated by LPS were able to activate T cells (16).
The idea that vascular DCs and macrophages are competent for antigen presentation is further supported by the finding that yellow fluorescent protein-expressing (YFP-expressing) CD11c-YFP ${ }^{+}$ cells isolated from normal mouse aorta can present model antigen to $T$ cells in vitro (14).

Here, we developed 2-photon live cell imaging of the mouse aorta to investigate whether aortic $\mathrm{CD} 11 \mathrm{c}^{+} \mathrm{APCs}$ can interact with and activate T cells. We observed that interaction of APCs with $\mathrm{CD} 4^{+}$ $\mathrm{T}$ cells resulted in secretion of the proinflammatory cytokines IFN- $\gamma$ and TNF- $\alpha$, which in turn led to increased uptake and accumulation of oxidized LDL (oxLDL) and minimally modified LDL 
A

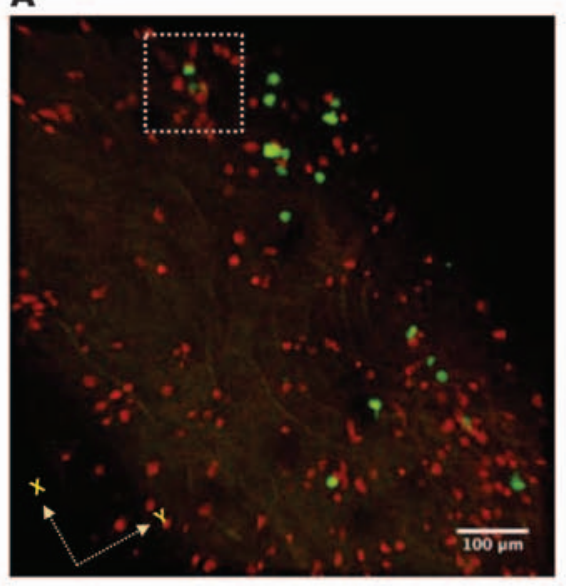

D

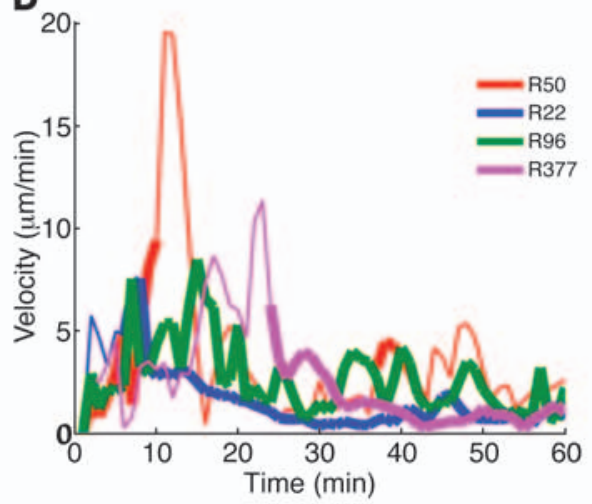

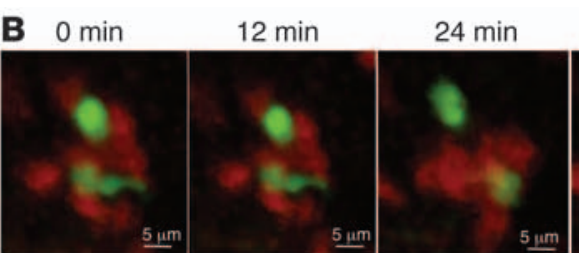

$36 \mathrm{~min}$

$48 \mathrm{~min}$

$60 \min$

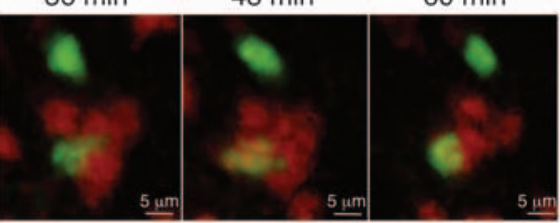

C

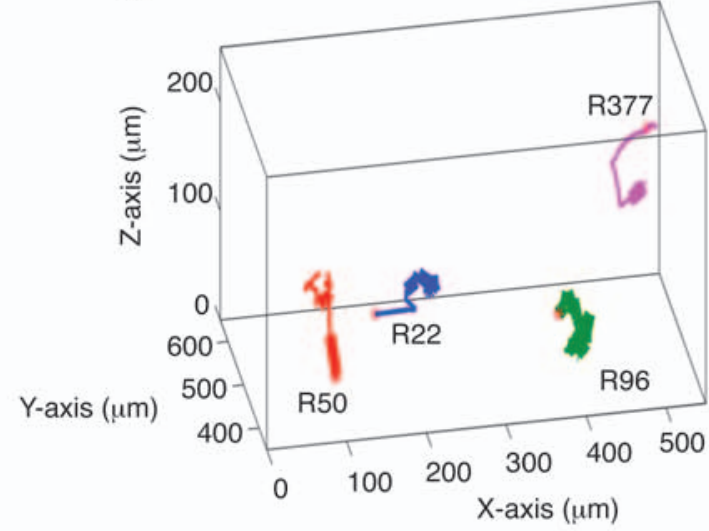

E

\section{F}

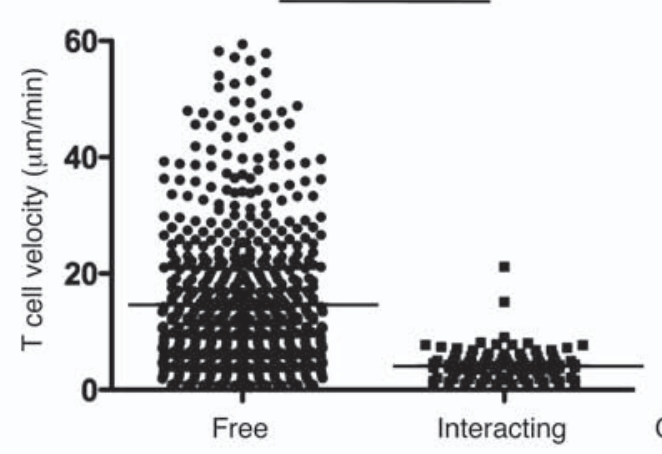

Figure 2

2-photon imaging of T cell-APC interaction in aortic wall. (A) Maximum intensity projection along $z$ axis (top view) through image stacks $(760 \times 760 \times 210 \mu \mathrm{m}[x, y, z])$. View of CD11c-YFP+ (green) and SNARF-labeled OTII T cells (red) from the adventitial side of explanted mouse aorta. (B) Time-lapse images of interacting APCs (green) and T cells (red) in the adventitia (boxed region in A) in the presence of OVA ${ }^{323-339}$. Tracks (C) and velocities (D) of individual T cells obtained from 3D projection (1 color per cell) in the presence of OVA ${ }^{323-339}$. Long interaction with APCs ( $>5$ minutes) is denoted by a thick line. (E) Velocities of individual noninteracting (free; $n=1,057)$ and interacting $(>5$ minutes; $n=99)$ T cells. Average is indicated by horizontal line. (F) Percent T cells interacting with APCs in the presence and absence of OVA ${ }^{323-339}$. Data (mean \pm SEM) are representative of at least 3 independent experiments. ${ }^{*} P<0.05$. Scale bars: $100 \mu \mathrm{m}(\mathbf{A}) ; 5 \mu \mathrm{m}(\mathbf{B})$.

$(\mathrm{mmLDL})$ in aortic macrophages. Our findings suggest that APC interactions with aortic $T$ cells restimulate previously activated $\mathrm{CD}^{+} \mathrm{T}$ cells, resulting in proinflammatory cytokine production, which in turn promotes lipid uptake and foam cell formation.

\section{Results}

Different myeloid cell subtypes are present in mouse aorta in atherosclerosis. Aortic leukocyte content expands more than 3-fold in Apoe ${ }^{-/}$mice (55). Here, we confirmed that feeding a fat-rich WD for 12 weeks dramatically increased $\mathrm{CD} 45^{+}$leukocyte number in aortas of Apoe ${ }^{-/-}$, but not normal C57BL/6 (B6), mice (Supplemental Figure $1 \mathrm{~A}$; supplemental material available online with this article; doi:10.1172/JCI61758DS1). To better understand the composition of the myeloid compartment, we analyzed aortic cell suspensions for expression of the integrin subunits CD11b $\left(\alpha_{M}\right)$ and
CD11c $\left(\alpha_{x}\right)$, both of which are well-recognized myeloid cell markers, by flow cytometry. $\mathrm{CD} 11 \mathrm{~b}^{+} \mathrm{CD} 11 \mathrm{c}^{-}$macrophages were present in B6 aortas, with some CD11 $\mathrm{b}^{+} \mathrm{CD} 11 \mathrm{c}^{+}$cells and a few CD11b CD $11 \mathrm{c}^{+}$DCs (Figure 1A and Supplemental Figure 1, B and C). The myeloid compartment in aortas of WD-fed Apoe $e^{-/-}$mice was dominated by $\mathrm{CD} 11 \mathrm{~b}^{+} \mathrm{CD} 11 \mathrm{c}^{-}$macrophages and almost as many $\mathrm{CD}_{11} \mathrm{~b}^{+} \mathrm{CD} 11 \mathrm{c}^{+}$cells (Supplemental Figure 1B), in agreement with the increase in aortic MOMA2 ${ }^{+} \mathrm{CD} 11 \mathrm{c}^{+}$cells during atherosclerosis described previously (56). Many CD $11 \mathrm{~b}^{+} \mathrm{CD} 11 \mathrm{c}^{+}$cells in aortas of WD-fed Apoe $e^{--}$mice also expressed high levels of MHC class II (Supplemental Figure 1, C and D). Some CD $11 \mathrm{~b}^{+} \mathrm{CD} 11 \mathrm{c}^{-}$and $\mathrm{CD} 11 \mathrm{~b}^{+} \mathrm{CD} 11 \mathrm{c}^{+}$cells expressed the macrophage marker $\mathrm{F} 4 / 80$ (Supplemental Figure 1D). Occasional $\mathrm{Ly}_{6} \mathrm{G}^{+}$neutrophils were also detected among $\mathrm{CD} 11 \mathrm{~b}^{+} \mathrm{CD} 11 \mathrm{c}^{-}$cells (Supplemental Figure 1D). Only CD $11 b^{-}$CD $11 c^{+}$cells were found to express CD205 
A

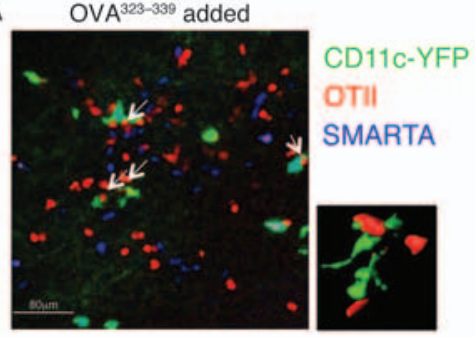

E SMARTA peptide added

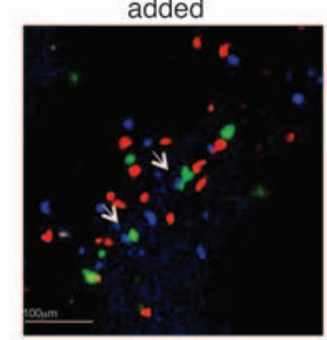

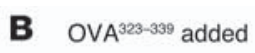

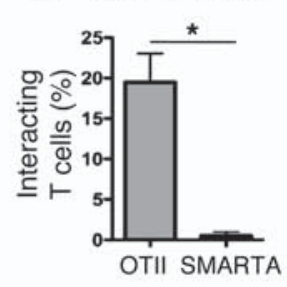

F SMARTA peptide added

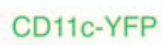

OTII SMARTA
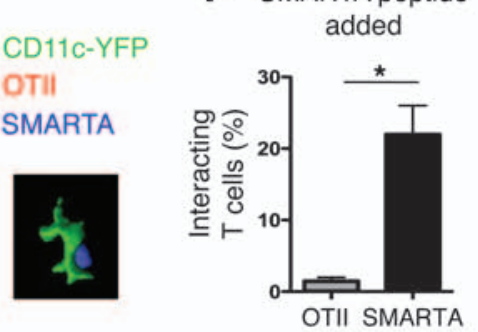

C

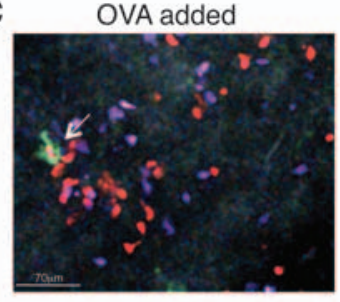

G

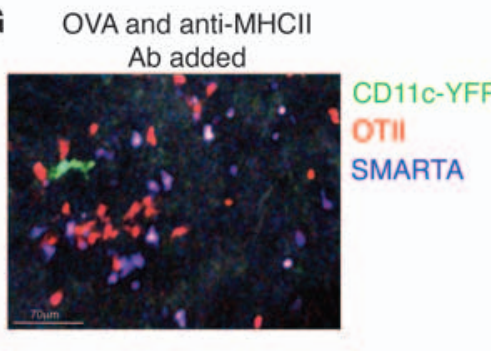

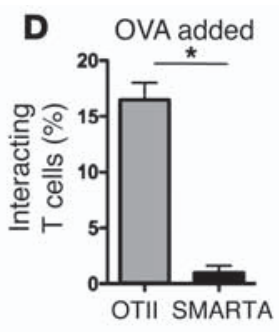

H OVA and anti-MHCI

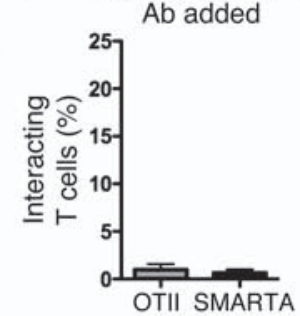

Figure 3

2-photon imaging of antigen-specific T cell-APC interaction in aortic wall. Interaction of CD11c-YFP+ APCs (green) with OTII T cells (red) or SMARTA T cells (blue) in the presence of $\operatorname{OVA}^{323-339}$ (A and B), OVA (C and D), SMARTA peptide (E and F), or OVA and anti-MHCII antibody $(\mathbf{G}$ and $\mathbf{H})$. Aortas were explanted from $A p o e^{-/-}$mice fed with WD for 12 weeks. See Supplemental Videos 5 and 6 for time series. (A, C, E, and G) Interacting APCs and T cells (white arrows) were located in the adventitia. Insets in $\mathbf{A}$ and $\mathbf{E}$ show surface-rendered OTII (A; enlarged $\times 8)$ or SMARTA (E; enlarged $\times 7$ ) T cells interacting with CD11c-YFP+ APCs. (B, D, F, and H) Percent interacting OTII and SMARTA T cells. Data are mean \pm SEM. Scale bars: $80 \mu \mathrm{m}(\mathbf{A}) ; 70 \mu \mathrm{m}(\mathbf{C}$ and $\mathbf{G}) ; 100 \mu \mathrm{m}(\mathbf{E})$.

(Supplemental Figure 1D). The phenotype of CD $11 \mathrm{~b}^{+} \mathrm{CD} 11 \mathrm{c}^{+}$cells suggests that they might represent a mixed population of macrophages and DCs (Supplemental Figure 1D and ref. 57).

In order to determine the location of these cells in the mouse aorta, we performed immunofluorescence staining for CD11b and CD11c (Figure 1, B and C, and Supplemental Figure 2). $\mathrm{CD} 11 \mathrm{~b}^{+} \mathrm{CD} 11 \mathrm{c}^{-}$cells were found in both atherosclerotic lesions and the lamina adventitia in WD-fed $A p o e^{-/-}$mice. In the adventitia, $\mathrm{CD} 11 \mathrm{~b}^{+} \mathrm{CD} 11 \mathrm{c}^{-}$cells were interdispersed with $\mathrm{CD} 11 \mathrm{~b}^{+} \mathrm{CD} 11 \mathrm{c}^{+}$and CD11 $b^{-} \mathrm{CD} 11 \mathrm{c}^{+}$cells (Figure 1C). Interestingly, large, round-shaped $\mathrm{CD}_{11} \mathrm{~b}^{+} \mathrm{CD} 11 \mathrm{c}^{+}$cells were localized in neointimal atherosclerotic lesions in $A_{p o e^{-/-}}$mice (Figure 1B), possibly representing foam cells.

$C D 11 c-Y F P^{+}$APCs present antigen to OTII CD $4^{+} T$ cells in the aortic wall of naive $B 6$ mice. Previous reports demonstrated that CD11c-YFP ${ }^{+}$ APCs purified from the aortic wall could present a model antigen in vitro (14). To directly test the function of vascular APCs inside the aortic wall, we used $C d 11 c-Y F P^{+}$mice, in which YFP is expressed under the Cd11c promoter (also known as Itgax ${ }^{Y F P}$ mice; ref. 58). In these mice, $C D 11 b^{+} C D 11 c^{+}$DCs express YFP at a level sufficient to be visualized by microscopy, whereas $\mathrm{CD} 11 \mathrm{~b}^{-} \mathrm{CD} 11 \mathrm{c}^{+}$cells remain $\operatorname{dim}$ (ref. 58 and Supplemental Figure 3, A and B). CD11c-YFP ${ }^{+}$cells were found in both the adventitia and the inner layers of the blood vessel (Supplemental Figure 3C). 2-photon microscopy of the aortic arch and valve areas revealed $\mathrm{YFP}^{+}$cells scattered in these areas (Figure $1 \mathrm{D}$ and data not shown). In atherosclerotic Apoe $e^{-/-} \mathrm{Cd} 11 \mathrm{c}-\mathrm{YFP}^{+}$ mice, $\mathrm{YFP}^{+}$cells were found in both the plaque and the adventitia (Figure 1E and Supplemental Video 1). YFP $\mathrm{FPCs}^{+}$in the aortic wall showed vigorous movement accompanied by large changes in shape, resulting in an average migration velocity of $1.36 \pm 0.14 \mu \mathrm{m} / \mathrm{min}$ (Supplemental Figure 4, A and B, and Supplemental Video 2). Thus, CD11 $\mathrm{c}^{+}$APCs appear to continuously scan the aortic wall.
To determine whether these APCs can present antigen to activated $\mathrm{CD}^{+} \mathrm{T}$ cells, we added labeled preactivated (anti-CD3 and anti$\mathrm{CD} 28) \mathrm{CD}^{+} \mathrm{T}$ cells isolated from OTII transgenic mice to explanted $\mathrm{CD} 11 \mathrm{c}-\mathrm{YFP}^{+}$aortas in the absence (data not shown) or presence of the antigenic peptide OVA ${ }^{323-339}$ (Figure 2, A and B) or whole OVA (Supplemental Figure 5) for 12 hours, followed by 2-photon imaging. Since draining lymph nodes are removed from the excised aortas, there is no possibility that $\mathrm{YFP}^{+} \mathrm{APCs}$ will leave and present the antigen outside the aortic wall, thus focusing observations on antigen presentation in the wall. We observed that OTII CD4 ${ }^{+} \mathrm{T}$ cells migrated into the aortic tissue and encountered multiple $\mathrm{YFP}^{+} \mathrm{APCs}$ (Figure 2, A and B, Supplemental Figure 5, A and B, and Supplemental Videos 3 and 4). In the absence of antigen, OTII cells migrated in apparently random patterns with large $x, y$, and $z$ components and high variations in velocities (data not shown). In contrast, in the presence of OVA, some $\mathrm{CD}^{+} \mathrm{T}$ cells showed long-lasting interactions with CD11c-YFP ${ }^{+}$cells (Figure 2, B-F, and Supplemental Figure 5B). Occasionally, CD4+ OTII T cells stopped in an area not occupied by $\mathrm{YFP}^{+}$cells, which suggests that cells interact with APCs that do not express YFP in $C d 11 c-Y F P^{+}$mice or encounter other barriers to their migration, such as areas of extracellular matrix that are organized in such a way as to hinder cell motility.

Consistent with observations in other nonlymphoid tissues, migrating $\mathrm{T}$ cells reduced their migration velocity from approximately $10 \mu \mathrm{m} / \mathrm{min}$ to approximately $2 \mu \mathrm{m} / \mathrm{min}$, approaching that of $\mathrm{YFP}^{+} \mathrm{APCs}$ (Figure 2, C-F). In contrast, in the absence of antigen, OTII cells migrated in apparently random patterns with large $x, y$, and $z$ components and high variations in velocities (data not shown). Taken together, our findings demonstrated that CD11c$\mathrm{YFP}^{+} \mathrm{DCs}$ can present model antigen and interact with $\mathrm{T}$ cells in the aortic wall of healthy $\mathrm{B} 6$ mice. 
A

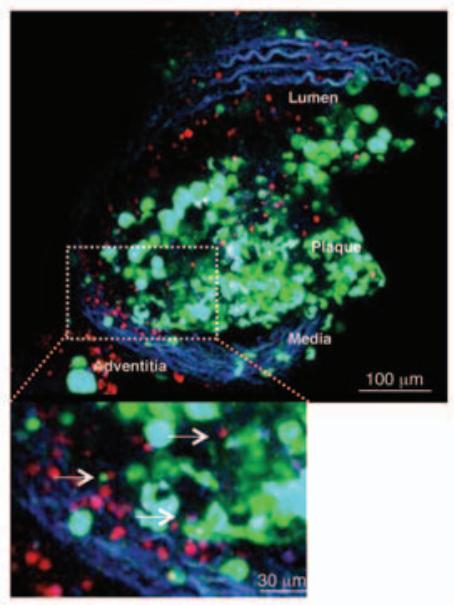

D

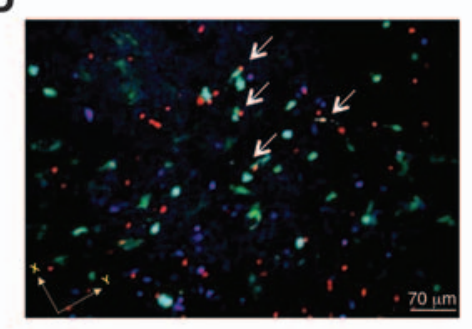

B
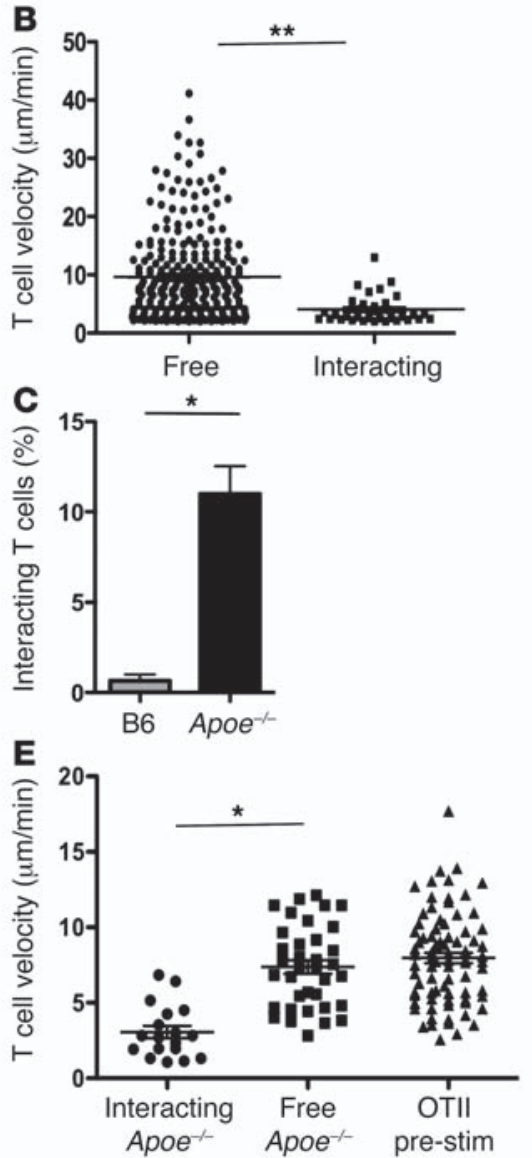

Figure 4

2-photon imaging of $\mathrm{Apoe}^{-/-} \mathrm{CD} 4^{+} \mathrm{T}$ cell-APC interaction in the plaque and adventitia of $\mathrm{Apoe}^{-/-}$aorta. (A) Cross-sectional view of innominate artery plaque and media. CD11C-YFP ${ }^{+}$cells are stained green, and SNARF-labeled $\mathrm{Apoe}^{-/-} \mathrm{CD} 4{ }^{+} \mathrm{T}$ cells are stained red. (B) Velocities of individual freely migrating $(n=126)$ and interacting $(n=47)$ T cells. No exogenous antigen was added. Average is indicated by horizontal line. (C) Percent interaction with CD11C-YFP+CD4+ $T$ cells isolated from spleens and lymph nodes of atherosclerotic WD-fed $\mathrm{Apoe}^{-/-}$or B6 mice. Data are mean \pm SEM of 2 independent experiments. (D) Maximum intensity projection (top view) through image stacks $(760 \times 760 \times 225 \mu \mathrm{m}[x, y, z])$. CD11c-YFP + cells are stained green, SNARF-labeled $\mathrm{Apoe}^{-/-}$ $\mathrm{CD} 4{ }^{+} \mathrm{T}$ cells are stained red, and CMRA-labeled OTII $\mathrm{CD}^{+} \mathrm{T}$ cells are stained blue. No antigen was added. Interacting cells (arrows) were located in the adventitia. See Supplemental Video 7. (E) Mean velocities of individual prestimulated (CD3/CD28) OTII and freely migrating or interacting $\mathrm{Apoe}^{-/-} \mathrm{CD} 4^{+} \mathrm{T}$ cells, isolated from $A_{p o e}{ }^{-/}$mice fed WD for 20 weeks. Average is indicated by horizontal line. ${ }^{*} P<0.05 ;{ }^{*} P<0.01$. Scale bars: $100 \mu \mathrm{m}$ (A); $30 \mu \mathrm{m}$ (A, inset); $70 \mu \mathrm{m}$ (D).
Antigen-specific interactions of CD11c-YFP ${ }^{+}$APCs with $C D 4^{+}$T cells in the aortic wall of atherosclerotic Apoe ${ }^{-/-}$mice. To address whether interactions between APCs and T cells in the aortic wall also occur in the context of atherosclerosis, we crossed $C d 11 c-Y F P^{+}$mice into the atherosclerosis-prone $A p o e^{-/-}$background (referred to herein as Apoe ${ }^{-/-} C d 11 c-Y F P^{+}$mice). To verify that productive T cell-APC interactions only occur in an antigen-dependent manner, we examined the behavior of T cells with 2 different antigen specificities simultaneously. OTII (labeled with SNARF) and SMARTA transgenic (labeled with CMRA) (59) T cells were coincubated with isolated aortas from WD-fed Apoe $e^{-/} C d 11 c-Y F P^{+}$mice. In the presence of OVA ${ }^{323-339}$ or whole OVA, SMARTA T cells randomly moved and did not interact with APCs, but OVA-specific OTII T cells were engaged in robust interactions with APCs, resulting in $\mathrm{T}$ cell-APC conjugate formation and overall decreased migration velocity of T cells (Figure 3, A-D, Supplemental Figure 6, A and C, and Supplemental Video 5). Conversely, addition of SMARTA peptide to this system led to an increased number of prolonged interactions of SMARTA, but not OTII, T cells with $\mathrm{YFP}^{+}$APCs (Figure 3, E and F, and Supplemental Video 6), resulting in a decrease of migration velocity of SMARTA T cells compared with OTII T cells (Supplemental Figure 6B). Furthermore, addition of MHCII blocking antibody to the system blocked interaction of $\mathrm{YFP}^{+}$APCs with antigen-specific OTII T cells in the presence of OVA (Figure 3, G and $\mathrm{H}$ ), resulting in increased migration velocity of OTII T cells (Supplemental Figure 6D). These data demonstrated antigen-specific T cell-APC interactions in aortas of atherosclerotic Apoe ${ }^{-/-} \mathrm{CD} 11 \mathrm{c}-\mathrm{YFP}^{+}$mice.
$\mathrm{CD}^{+}$T cells isolated from Apoe ${ }^{-/-}$mice interact with DCs in atherosclerotic plaques. Having shown model antigen-specific $\mathrm{T}$ cell interactions with APCs in atherosclerotic mouse aortas, we next tested whether endogenous antigens can also support such interactions. The ApoB100 component of LDL has been proposed as one of the most relevant antigens in atherosclerosis (47). Alternatively, HSP60 (60) and oxLDL (44) have also been proposed as potential atherosclerosis autoantigens. We reasoned that atherosclerotic Apoe $e^{-/-}$mice should contain polyclonal antigen-experienced $T$ cells specific for atherosclerosis antigens that should interact with APCs. To test this, isolated aortas from WD-fed $A p o e^{-/-} \mathrm{CD} 11 \mathrm{c}-\mathrm{YFP}^{+}$mice were incubated with $\mathrm{CD}^{+} \mathrm{T}$ cells sorted from the spleen and lymph nodes of WD-fed $\mathrm{Apoe}^{-/-}$mice. In these experiments, no external antigens were added. Similar to anti-CD3/CD28-prestimulated OTII T cells, Apoe $^{-/-} \mathrm{CD}^{+} \mathrm{T}$ cells efficiently migrated into the aortic wall and into the plaque, even without additional ex vivo stimulation. Some of them participated in long interactions with some APCs in the plaque and in the adventitia (Figure 4A). The percentage of interacting cells was lower than in the TCR transgenic OTII system, likely reflecting the polyclonal nature of atherosclerotic T cells (Supplemental Video 6). Similar to our experiments with model antigen, we observed decreased migration velocities for $\mathrm{CD}^{+} \mathrm{T}$ cells interacting with APCs (Figure 4B). Control CD4 ${ }^{+} \mathrm{T}$ cells obtained from $\mathrm{B} 6$ mice entered the aortic tissue in lower numbers and showed only a few interactions with $\mathrm{YFP}^{+} \mathrm{APCs}$ (Figure 4C).

To directly compare the movement of $A p o e^{-/-} \mathrm{T}$ cells with prestimulated OTII T cells, we coincubated both cell types (labeled with different fluorochromes) with atherosclerotic aortas. With- 

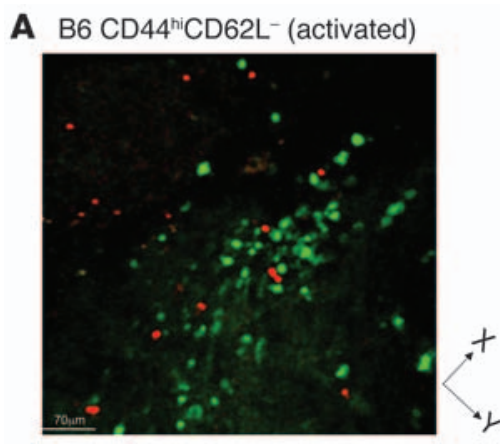

C

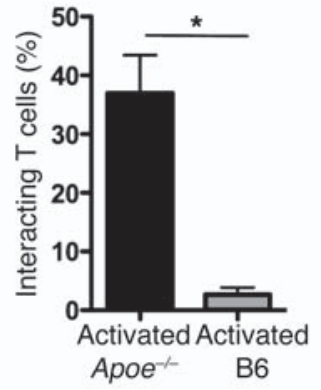

B

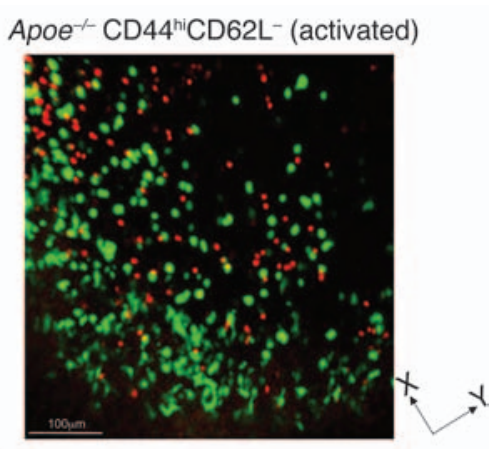

D

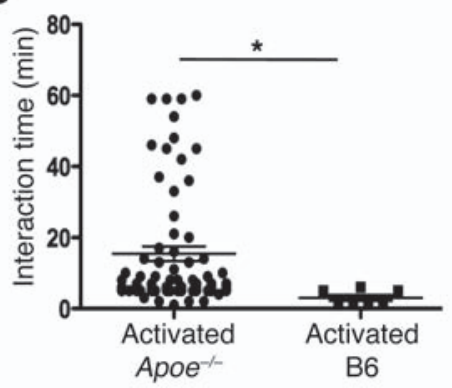

Figure 5

2-photon imaging of interactions of activated B6 or Apoe ${ }^{-/-} \mathrm{CD} 4+$ T cells with APCs in the adventitia of atherosclerotic aorta. (A and $\mathbf{B}$ ) Maximum intensity projection along $z$ axis (top view) through image stacks $(760 \times 760 \times 225 \mu \mathrm{m}[x, y, z])$. CD11c-YFP+ cells are

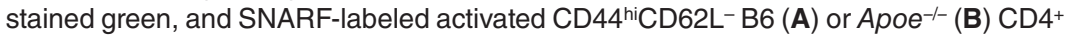
T cells are stained red. (C) Percent interacting CD11c-YFP+ APCs and CD44 ${ }^{\text {hi }}$ CD62 $^{-}$ $\mathrm{CD}^{+} \mathrm{T}$ cells isolated from atherosclerotic WD-fed $\mathrm{Apoe}^{-/-}$or $\mathrm{B} 6$ mice. (D) Interaction times between $\mathrm{CD} 11 \mathrm{c}-\mathrm{YFP}^{+} \mathrm{APC}$ and $\mathrm{Apoe}^{-/}$or B6 CD44 ${ }^{\text {hi }} \mathrm{CD} 62 \mathrm{~L}^{-} \mathrm{CD} 4{ }^{+} \mathrm{T}$ cells. Each symbol represents $1 \mathrm{~T}$ cell-APC interaction. Data are mean \pm SEM. ${ }^{*} P<0.05$. Scale bars: $70 \mu \mathrm{m}(\mathbf{A}) ; 100 \mu \mathrm{m}$ (B).

out addition of antigen, the movement of free $\mathrm{CD}^{+} \mathrm{Apoe}^{-/-} \mathrm{T}$ cells was similar to that of in vitro prestimulated OTII T cells (Figure 4, D and E, and Supplemental Video 6). A portion of Apoe $e^{-/}$, but not OTII, T cells participated in long-lasting interactions with $\mathrm{YFP}^{+}$ APCs, sometimes staying attached to APCs for the entire observation period (Figure $4 \mathrm{D}$ ), which decreased the migration velocity of interacting $\mathrm{CD}^{+} \mathrm{Apoe}^{--} \mathrm{T}$ cells (Figure 4E). Importantly, when OVA $^{323-339}$ was added to the aorta, we observed multiple interactions of OTII T cells with CD11c-YFP ${ }^{+}$cells (data not shown; similar to Figure $2 \mathrm{~A}$ ).

To compare the interaction efficiency of $\mathrm{CD} 4^{+} \mathrm{T}$ cells in the aorta and peripheral lymph node, Apoe $e^{--}$mice were injected with $\mathrm{CD}^{+} \mathrm{T}$ cells obtained from spleens of $\mathrm{B} 6$ or $A p o e^{-/-}$mice fed WD for 12 weeks. 12 hours after injections, paraaortic lymph nodes were isolated and imaged. We found a small decrease in migration speed of Apoe $e^{-/-} \mathrm{CD} 4^{+} \mathrm{T}$ cells compared with $\mathrm{B} 6 \mathrm{CD} 4^{+} \mathrm{T}$ cells (Supplemental Figure 7), which suggests that a small percentage of Apoe $e^{--} \mathrm{T}$ cells participated in interactions with APCs in the paraaortic lymph node.

We reasoned that activated $\mathrm{T}$ cells from Apoe-/- mice may interact more efficiently with APCs in mouse aortas and atherosclerotic plaques, because of an expected higher frequency of atherosclerosis antigen-specific T cells in Apoe $e^{-/-}$compared with B6 mice. To test this, we sorted activated $\left(\mathrm{CD} 44^{\mathrm{hi}} \mathrm{CD} 62 \mathrm{~L}^{-}\right) \mathrm{CD} 4^{+} \mathrm{T}$ cells from normal $\mathrm{B} 6$ or $A p o e^{-/-}$mice after 12 weeks of WD feeding and incubated them with atherosclerotic aortas from $A p o e^{-/-C d 11 c-}$

$\mathrm{YFP}^{+}$mice. We found that a few $\mathrm{CD} 44^{\mathrm{hi}} \mathrm{CD} 62 \mathrm{~L}$ $\mathrm{B} 6 \mathrm{CD}^{+} \mathrm{T}$ cells migrated in to the atherosclerotic aortas and exhibited occasional interactions with CD11c-YFP ${ }^{+} \mathrm{APCs}$ (Figure $5 \mathrm{~A}$ ). In contrast,

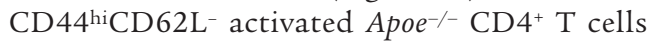
readily entered atherosclerotic plaque and interacted with CD11c-YFP ${ }^{+}$APCs (Figure 5B). Many of CD44hiCD62 $\mathrm{L}^{-} \mathrm{Apoe}^{-/-} \mathrm{CD} 4^{+}$cells participated in interactions with CD11c-YFP ${ }^{+} \mathrm{APCs}$ (Figure 5C) and showed long interaction times (Figure 5D). These data demonstrated that under atherosclerotic conditions, $\mathrm{T}$ cells from atherosclerotic Apoe $e^{-/}$mice enter the plaque and adventitia and interact with APCs.

Antigen presentation in the aortic wall leads to increased $T$ cell activation and proliferation as well as cytokine production. Successful activation of T cells by APCs leads to proliferation, activation, polarization, and secretion of cytokines (61). We therefore examined whether antigen-dependent activation of $\mathrm{T}$ cells in the aortic wall also triggers cytokine production. We incubated sorted $\mathrm{CD} 44^{\mathrm{hi}} \mathrm{CD} 62 \mathrm{~L}^{-}$ activated or $\mathrm{CD} 44^{\mathrm{lo}} \mathrm{CD} 62 \mathrm{~L}^{+}$naive $\mathrm{CD} 4^{+} \mathrm{T}$ cells isolated from B6 or Apoe-/- mice with atherosclerotic aortas without additional antigens. Activated $A p o e^{-1-} \mathrm{T}$ cells induced significant secretion of IFN- $\gamma$ from Apoe ${ }^{-/-}$aortas (Figure 6A). Neither $A p o e^{-/-}$nor B6 naive T cells could induce IFN- $\gamma$ production when incubated with Apoe $e^{-/}$aortas. Activated $\mathrm{B} 6 \mathrm{CD}^{+} \mathrm{T}$ cells were also unable to promote IFN- $\gamma$ expression (Figure 6A). Apoe ${ }^{-/}$aortas secreted some TNF- $\alpha$, and its expression was not further enhanced by either naive or activated $\mathrm{B} 6$ $\mathrm{CD}^{+} \mathrm{T}$ cells or by naive Apoe ${ }^{-/-} \mathrm{CD} 4^{+} \mathrm{T}$ cells. Notably, only addition of CD44 $4^{\text {hi }} \mathrm{CD} 62 \mathrm{~L}^{-}$activated Apoe $e^{-1-} \mathrm{T}$ cells significantly enhanced TNF- $\alpha$ production. (Figure 6A). Secretion of IFN- $\gamma$ and TNF- $\alpha$ was also increased when OTII cells were incubated with $\mathrm{CD} 11 \mathrm{c}-\mathrm{YFP}^{+} / \mathrm{B} 6$ aortas in the presence of OVA (data not shown), which demonstrated that $\mathrm{T}$ cell antigen specificity, not atherosclerotic conditions per se, is important for inflammatory cytokine production. To measure $\mathrm{T}$ cell proliferation in vivo, we used in vivo BrdU pulse labeling, which revealed increased $T$ cell proliferation in the aortas of WD-fed Apoe ${ }^{-/-}$versus B6 mice (Figure 6, B and C). These data suggest that productive interactions between APCs and $\mathrm{T}$ cells in the aortic wall lead to $\mathrm{T}$ cell proliferation and production of the inflammatory cytokines IFN- $\gamma$ and TNF- $\alpha$.

Administration of proinflammatory cytokines increases oxLDL and $m m L D L$ uptake in aortic $C D 11 b^{+}$macrophages. To test whether cytokines produced in response to interactions with APCs in the vessel wall can influence foam cell formation through the uptake of modified LDL, we cocultured isolated aortas with OTII T cells in the absence or presence of OVA ${ }^{323-339}$, followed by addition of oxLDL or mmLDL (both of which are known to be readily internalized by macrophages; ref. 7). We found that uptake of oxLDL by $\mathrm{CD} 11 \mathrm{~b}^{+} \mathrm{CD} 11 \mathrm{c}^{-}$cells was significantly increased in the presence of antigen (Figure 7, A and B). Expression of CD36 (a main receptor for oxLDL uptake) and MHCII was also upregulated (Figure 7A). Disruption of T cell-APC interaction by the addition of an MHCII blocking antibody decreased oxLDL accumulation in $\mathrm{CD} 11 \mathrm{~b}^{+} \mathrm{CD} 11 \mathrm{c}^{-}$cells (Figure $7, \mathrm{C}$ and $\mathrm{D}$ ). $\mathrm{mmLDL}$ is also 


\section{A}

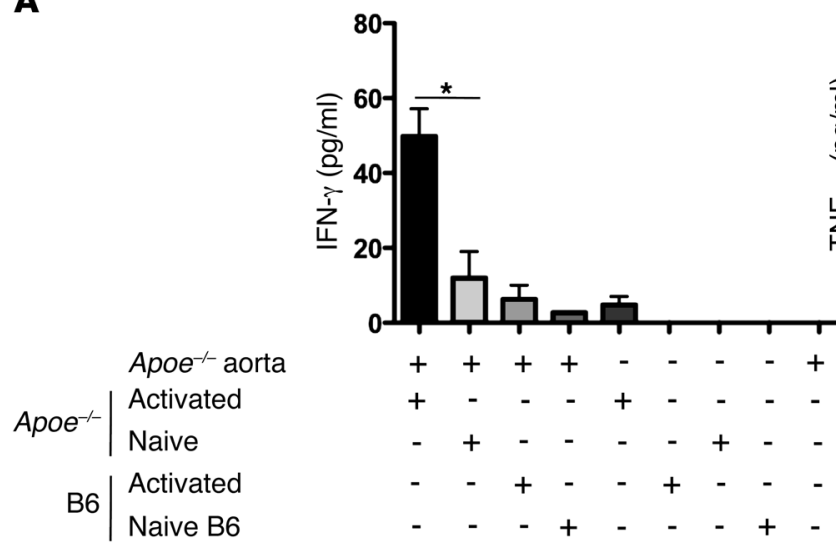

B

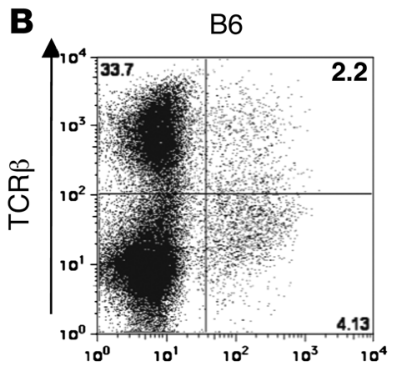

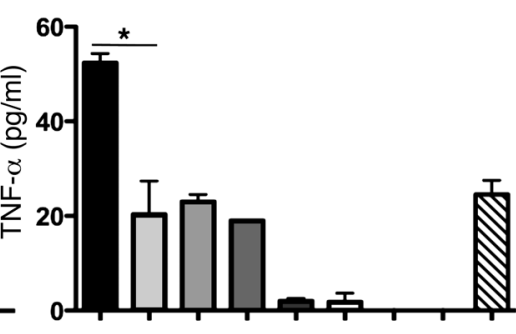

$+++\quad+\quad-\quad-\quad-+$

$+\quad-\quad+\quad-\quad-\quad-$

$-+-\quad-\quad+\quad-$

$-\quad+-\quad+--$

$\begin{array}{lllllllll}- & - & + & - & - & + & - & - & - \\ - & - & - & + & - & - & - & + & -\end{array}$

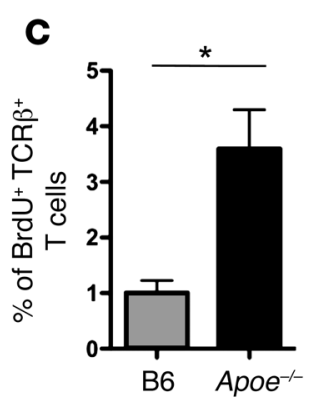

Figure 6

Cytokine secretion and $\mathrm{T}$ cell proliferation in mouse aorta. (A) IFN- $\gamma$ and TNF- $\alpha$ protein levels from supernatants of explanted intact $\mathrm{Apoe}^{-/-}$ aortas incubated with sorted $\mathrm{CD} 44^{\circ}{ }^{\circ} \mathrm{CD} 62 \mathrm{~L}^{+}$naive or CD44 ${ }^{\text {hiCD62L- }}$ activated (effector-memory) CD4+ $\mathrm{T}$ cells isolated from $\mathrm{Apoe}^{-/-}$ or $\mathrm{B} 6$ mice. No antigen was added. Average of 3 independent experiments. (B and $\mathbf{C}$ ) Aortic TCR $\beta^{+}$T cell proliferation was analyzed by i.p. BrdU injection 24 and 12 hours prior to collection of aortas. Aortas of B6 $(n=4)$ and Apoe $^{-/-}(n=8)$ mice after 15 weeks of WD feeding were digested and stained for aorta-infiltrating cells. Numbers indicate percentage in each quadrant. Data are mean \pm SEM. ${ }^{\star} P<0.05$. taken up by macrophages, but uses a different mechanism (62, 63). mmLDL uptake by macrophages was enhanced in the presence of model antigen (Figure 7, E and F), and this was reduced in the presence of a blocking MHCII antibody (Figure 7, G and $\mathrm{H})$. These data suggest that uptake of both oxLDL and mmLDL is enhanced in the presence of antigen. Taken together with the data in Figures 5 and 6, our results demonstrated that cytokines secreted by effector-memory (i.e., activated CD $44^{\text {hi }}{ }^{\text {CD } 62 L^{-}}$) CD4 ${ }^{+}$ $\mathrm{T}$ cells in response to antigen presentation by $\mathrm{CD} 11 \mathrm{c}^{+} \mathrm{APCs}$ enhance uptake of oxLDL and $\mathrm{mmLDL}$, thereby promoting foam cell formation from aortic macrophages.

Depletion of $C D 11 b^{-} C D 11 c^{+}$cells decreases inflammatory cytokine production. To examine the role of APCs and antigen presentation in aortic inflammation and foam cell formation, we crossed Cd11c-DTR ${ }^{+}$mice to atherosclerosis-prone Apoe ${ }^{-/-}$mice to directly investigate the effect of CD11 $\mathrm{c}^{+}$cell depletion on atherosclerosis development. Since multiple injections of diphtheria toxin (DT) are only possible in bone marrow-transplanted mice $(64,65)$, we transplanted lethally irradiated Apoe $e^{-/-}$mice with $A p o e^{-/-} \mathrm{Cd} 11 \mathrm{c}$ $D T R^{+}$bone marrow. 4 weeks after bone marrow transplantation, mice were fed WD for 12 weeks; during the last 2 weeks of WD feeding, mice were injected with DT every other day. Flow cytometry revealed a decrease in accumulation of hematopoietic $\left(\mathrm{CD} 45^{+}\right)$ cells in the aortas of DT-treated mice (data not shown). The most significant depletion was seen in $\mathrm{CD}_{11} \mathrm{~b}^{-} \mathrm{CD} 11 \mathrm{c}^{+}$cells in the aortas and spleens of DT-treated mice, whereas CD11 $b^{+} \mathrm{CD} 11 \mathrm{c}^{+}$cell numbers were only partially reduced by DT treatment (Figure 8, A and $\mathrm{B}$ ). To assay the effect of DC depletion on oxLDL uptake, we injected Apoe ${ }^{-/-} C d 11 c-D T R^{+}$mice with a single dose of DT. 24 hours later, aortas were harvested and incubated with OTII T cells in the presence of OVA and oxLDL as described above. Importantly, we found $20 \%$ decreased uptake among CD $11 \mathrm{~b}^{+} \mathrm{CD} 11 \mathrm{c}^{-}$cells in aortas of DT-treated animals compared with the control (Figure 8C). Realtime PCR analysis demonstrated a significant reduction of $I l 6$ and Il12p35 proinflammatory cytokine expression in the aortas of DTtreated mice (Figure 8D). Taken together, these data suggested that transient depletion of DCs reduces oxLDL uptake and cytokine expression in the aortas of DT injected $\mathrm{Apoe}^{-/-} \mathrm{Cd} 11 \mathrm{c}-\mathrm{DTR} \mathrm{R}^{+}$mice.

\section{Discussion}

In the last decade, it has become increasingly clear that chronic inflammation is a major factor in the development and progression of atherosclerosis (66). Components of both innate and adaptive immunity have been implicated in disease initiation and progression $(1,3)$. DCs and macrophages represent classical professional APCs, and their numbers increase significantly during atherosclerosis progression in aortas $(6,55)$.

We found here that $\mathrm{CD} 11 \mathrm{~b}^{+} \mathrm{CD} 11 \mathrm{c}^{+}$cells extensively infiltrated the atherosclerotic aorta, where they resided both in the plaque and adventitia, potentially giving rise to $\mathrm{CD} 11 \mathrm{~b}^{+} \mathrm{CD} 11 \mathrm{c}^{+}$foam cells in the plaque. These cells showed high surface expression levels of MHCII and the costimulatory molecules CD80 and CD86, characterizing them as specialized and mature APCs. Some of these cells also expressed F4/80, which suggests that this heterogeneous population of $\mathrm{CD} 11 \mathrm{~b}^{+} \mathrm{CD} 11 \mathrm{c}^{+}$cells includes both DCs and macrophages.

Accumulating evidence suggests the possibility of direct T cellDC interaction and antigen presentation in the aorta during induction and progression of atherosclerosis $(14,16,18,51-54)$. Here, using 2-photon microscopy, we were able to visualize T cell-APC interactions in the explanted mouse aorta. We showed that aortic APCs engaged in antigen-specific interactions with $\mathrm{CD} 4^{+} \mathrm{T}$ cells, 
A
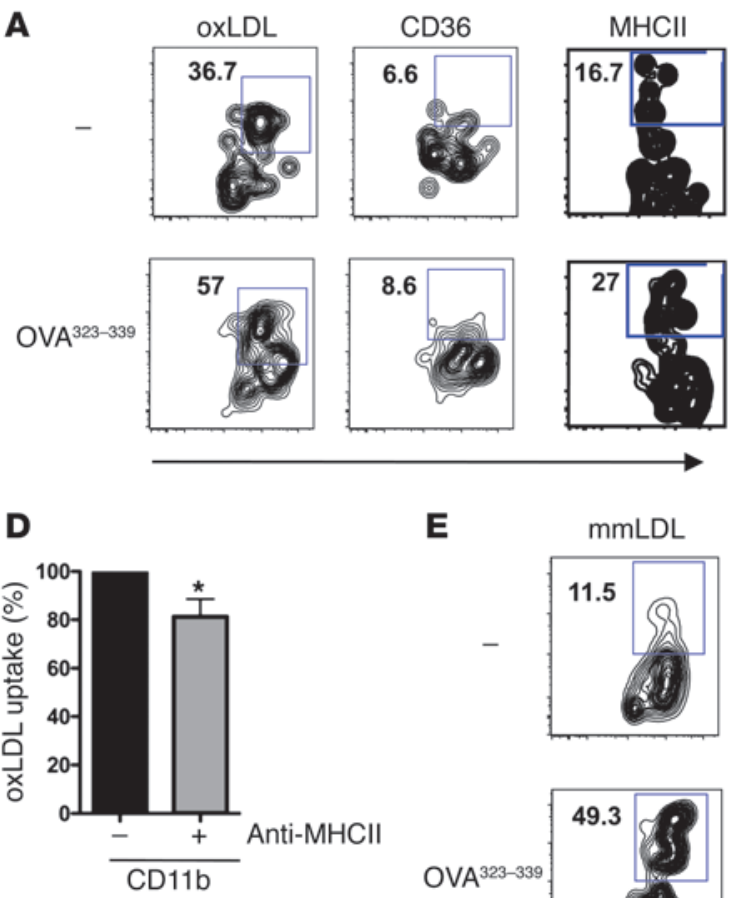

E

$\mathrm{mmLDL}$
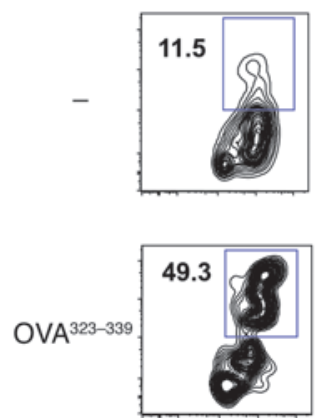

B
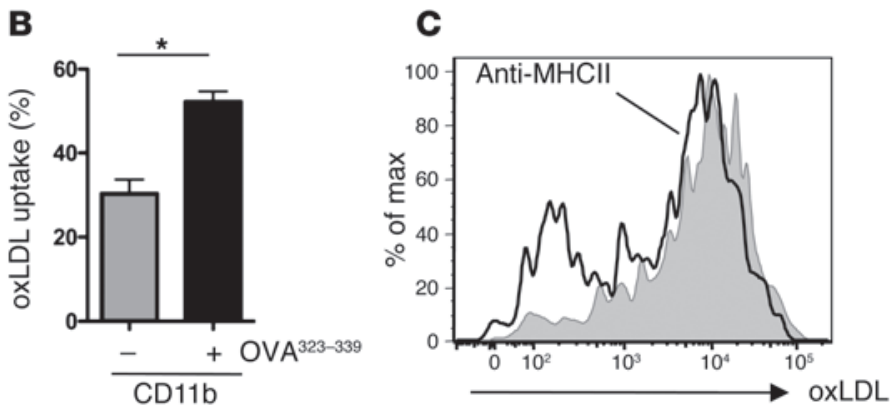

CD11b

CD36

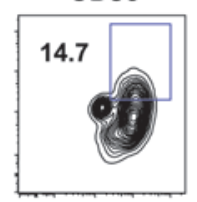

39.4

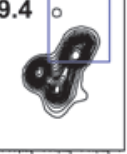

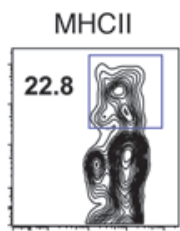

56.3

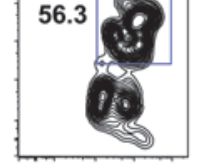

F

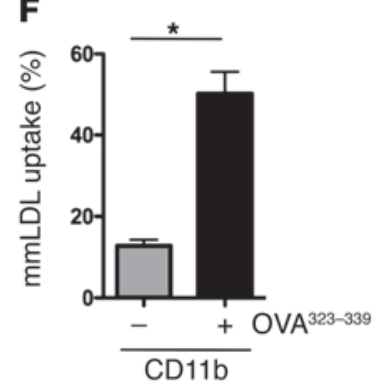

G

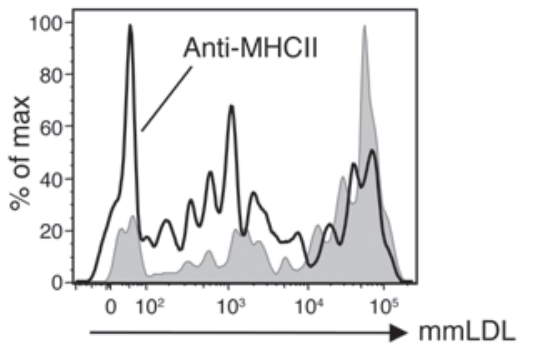

H

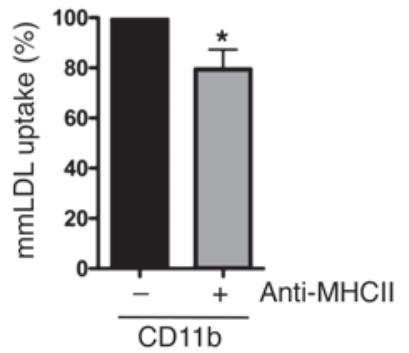

Figure 7

oxLDL and mmLDL uptake and foam cell formation in mouse CD11 b+ aortic macrophages. Uptake of oxLDL (A) or mmLDL (E), CD36, and MHCII expression in $\mathrm{CD} 11 \mathrm{~b}^{+}$macrophages in explanted aortas cultured with OTII T cells in the presence or absence of OVA ${ }^{323-339}$. Shown are representative experiments. Average \pm SEM oxLDL (B) or mmLDL (F) uptake in 3 independent experiments. oxLDL (C) and $\mathrm{mmLDL}(\mathbf{G})$ in $\mathrm{CD} 11 \mathrm{~b}^{+}$ aortic macrophages, measured in the presence of OVA ${ }^{323-339}$ with (open histograms) or without (filled filled histograms) MHCII blocking antibody.

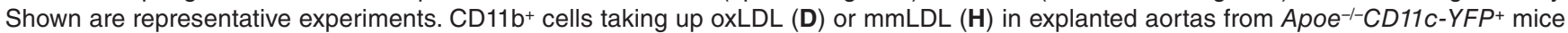
cultured with OTII T cells in the presence of OVA ${ }^{323-339}$ with or without anti-MHCIl antibody. Data (mean \pm SEM) are expressed as a percentage of the untreated value. ${ }^{*} P<0.05$.

which led to $T$ cell proliferation and production of IFN- $\gamma$ and TNF- $\alpha$ in the aorta. Since both T cell and APC numbers dramatically expand upon atherosclerosis progression, the number of their interactions may increase, leading to enhanced production of proatherogenic cytokines. Proinflammatory cytokines resulting from these interactions promoted uptake of oxLDL and mmLDL in macrophages in the aortic wall. Thus, our data identified a plausible mechanism by which the adaptive immune system contributes to atherosclerosis. Even though our results were obtained using an ex vivo approach, the antigen-specific interaction between $\mathrm{T}$ cells and APCs likely takes place and is important in vivo. However, other factors, such as intact circulation, ongoing recruitment of infiltrating leukocytes, systemic inflammatory responses, and intact lymphatic drainage, could also be important contributors to atherogenesis.
The contribution of myeloid cells to atherosclerosis is often envisioned only with regard to their ability to sustain inflammation via cytokine production, to take up lipids, and to differentiate into foam cells, thereby increasing plaque size (12). Our data suggest that myeloid cells can also be involved in processing and presentation of antigens, resulting in antigen-dependent reactivation of T lymphocytes.

Previous work has suggested that oxLDL (44), HSP60 $(60,67)$, or ApoB100 (47) may represent possible atherosclerosis autoantigens. Our study did not address the identity of the atherosclerosis antigens, but showed that activated $\mathrm{CD}^{+} \mathrm{T}$ cells from $A p o e^{-/-}$mice participated in interactions with $\mathrm{CD} 11 \mathrm{c}^{+} \mathrm{APC}$ and induced production of IFN- $\gamma$ and TNF- $\alpha$ when incubated with Apoe $e^{-/}$aortas. Gene-deficient mice lacking the costimulatory molecules CD80 and 
A

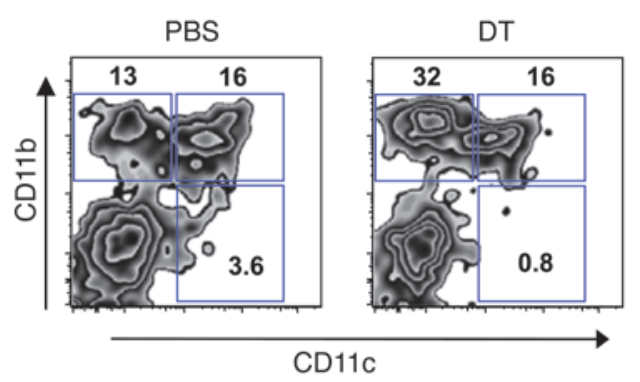

C

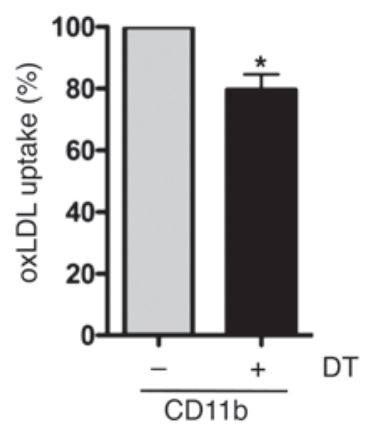

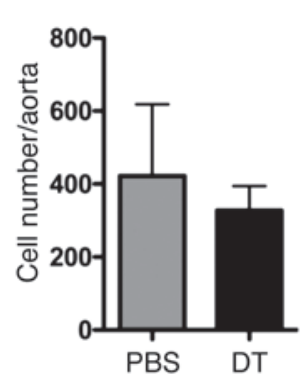

D

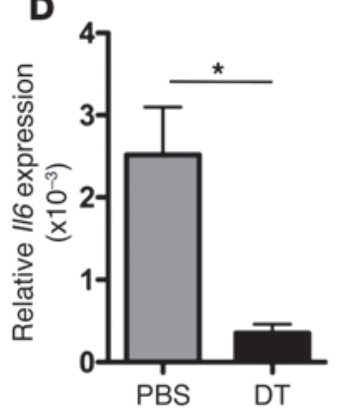

$\mathrm{CD} 11 \mathrm{~b}+\mathrm{CD} 11 \mathrm{c}$
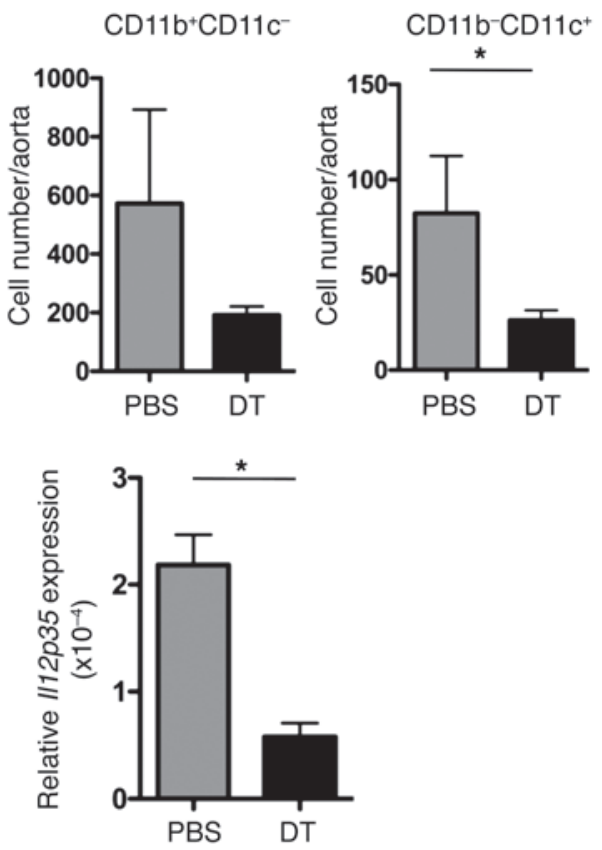

\section{Figure 8}

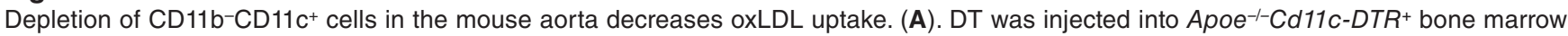
chimeric mice fed WD for 12 weeks during the last 2 weeks of WD feeding. Aortas was harvested, digested, and stained for CD11b and CD11C.

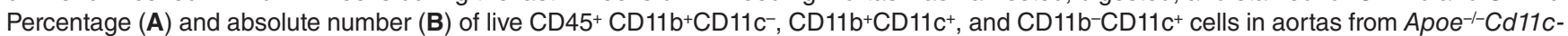
$D T R^{+}$mice injected with DT $(n=5)$ or vehicle control $(n=5)$. (C) Percent CD11 b+ cells taking up oxLDL in explanted aortas from 24-hour CD11cdepleted and nondepleted $\mathrm{Apoe}^{--} \mathrm{Cd11C-DTR^{+ }}$ mice cultured with OTII T cells in the presence of OVA ${ }^{323-339}$. Data (average of 3 independent experiments) are expressed as a percentage of oxLDL uptake in the absence of CD11c depletion. (D) Expression of $/ / 6$ and $/ / 12 p 35$, as determined by real-time PCR, in aortas of mice as in A. Data are mean \pm SEM. ${ }^{*} P<0.05$.

CD86 have previously been shown to have reduced atherosclerosis (48). Our data suggest that this may be explained, at least in part, by defective antigen presentation in the vessel wall. The important role of DCs and macrophages is further supported by prior reports that mice lacking CX3CR1, CCR2, or CCR5 also show reduced myeloid cell content in the artery wall and decreased plaque burden (68-70). Given the heterogeneity of myeloid cell populations, it is possible that different subsets of DCs play different roles. A recent study suggested that $\mathrm{CD} 103^{+} \mathrm{CD} 11 \mathrm{c}^{+}$DCs in the arterial wall could play an immunoregulatory role by supporting Treg development (17). $\mathrm{Ldlr}^{/-}$mice lacking Flt3, a receptor important for development and expansion of some DCs, show fewer CD $103^{+}$DCs in the aorta, which correlated with a small increase in atherosclerotic lesion size (17). On the other hand, DC subsets, including CD11 $\mathrm{c}^{+} \mathrm{CD} 11 \mathrm{~b}^{-}$ and $\mathrm{CD} 11 \mathrm{~b}^{+} \mathrm{CD} 11 \mathrm{c}^{+}$cells, may be pivotal for $\mathrm{T}$ cell activation and inflammation during atherosclerosis, similar to their well-defined role in immune responses. Depletion of DCs has also been shown to elevate circulating LDL cholesterol (71). Thus, the observed reduction of lesion size after depletion of APCs in Cd11c-DTR ${ }^{+}$mice in our study may represent the sum total of all these effects.

Antigen presentation to T cells by APCs in the context of atherosclerosis has been proposed to entail APCs capturing antigen in the vessel wall and then migrating to draining lymph nodes to present this antigen to T cells (72). However, the absence of lymphatic vessels in atherosclerotic plaques (73) and altered homing properties of APCs under hypercholesterolemic conditions (19) have been postulated to decrease or abrogate the ability of APCs to migrate to lymph nodes. In addition, chemokines and adhesion molecules such as CCL19, CCL21, P-selectin, and VCAM-1 within the developing atherosclerotic lesion may favor recruitment and retention of APCs, rather than their egress (73-75). Therefore, an alternative and largely unexplored possibility is that tissue-residing and newly recruited APCs capture and process antigens, present them, and activate T cells in the aorta's atherosclerotic environment. Through interactions with APCs in the arterial wall, T cells support the persistence of local chronic inflammation and promote atherosclerosis development.

Our 2-photon imaging experiments showed that $\mathrm{CD}^{+} \mathrm{T}$ cells underwent productive interactions with $\mathrm{CD} 11 \mathrm{c}^{+} \mathrm{APCs}$ in the aortic wall in the absence of secondary lymphoid organs. These interactions were strictly antigen dependent and more frequent with CD $44{ }^{\text {hi }} \mathrm{CD} 2 \mathrm{~L}^{-}$activated Apoe $e^{-/-} \mathrm{CD}^{+} \mathrm{T}$ cells. T cells engaged in long interactions with APCs in the vessel wall showed slow migration speeds, similar to those previously observed for T cell-DC interactions in other nonlymphoid organs (22-24). The productiveness of these interactions was demonstrated by subsequent $\mathrm{T}$ cell proliferation and induction of proinflammatory cytokine production, particularly IFN- $\gamma$ and TNF- $\alpha$. The functionality of these cytokines in atherosclerosis has previously been established. IFN- $\gamma$ gene ablation $(76,77)$ or blockade of TNF signaling $(78)$ relieves atherosclerosis, which suggests that the cytokines induced by APC interactions with $\mathrm{T}$ cells participate in atherosclerosis progression. The function of these cytokines in atherosclerosis is multifaceted and likely includes many different cell types and functional outcomes, such as chemokine production, cell recruitment, and cell maturation (11). 
Previous work has suggested that distinct cytokines can influence lipid uptake and differentiation of macrophages to foam cells (79). SR-PSOX (CXCL16), one of the receptors for oxLDL, is expressed in human and mouse atherosclerotic lesions. In a myeloid cell line (THP-1), IFN- $\gamma$ induced CXCL16 expression, suggesting at least one pathway by which IFN- $\gamma$ could be proatherogenic and directly affect foam cell differentiation. Here, we showed that proinflammatory cytokines produced in response to antigen presentation enhanced uptake of oxLDL and mmLDL in primary aortic macrophages. Several lines of evidence suggested that IFN- $\gamma$ coming from T cells activated in the aortic wall further regulates lipid uptake and foam cell formation. First, its production was stimulated by T cell-APC interactions in a strictly antigen-dependent manner. Second, exogenous IFN- $\gamma$ enhanced mmLDL uptake. Third, blockade of CD $4^{+}$ $\mathrm{T}$ cell-APC interaction by anti-MHCII antibody decreased oxLDL and mmLDL uptake. Fourth, transient depletion of DCs in Apoe $e^{-/}$ $C d 11 c-D T R^{+}$mice also decreased oxLDL uptake in explanted aortas.

The main cell type that we were able to visualize in the aorta by live cell imaging engaged in productive interactions with $\mathrm{T}$ cells and expressed both CD11b and CD11c. Since these cells increased dramatically in number during the progression of atherosclerosis and expressed high levels of MHCII and costimulatory molecules, these double-positive $\mathrm{CD} 11 \mathrm{~b}^{+} \mathrm{CD} 11 \mathrm{c}^{+} \mathrm{APC}$ may emerge as central drivers of the atherosclerotic process. They presented antigen and induced $\mathrm{T}$ cell cytokine production. Since foam cell formation is regulated by cytokines, whose production is induced upon $\mathrm{T}$ cell activation executed by myeloid cells in the aortic wall, our findings provide a plausible link between the adaptive and innate immune systems in atherosclerosis.

In summary, we conclude that interaction of CD $11 \mathrm{~b}^{+} \mathrm{CD} 11 \mathrm{c}^{+}$ APCs with $\mathrm{CD}^{+} \mathrm{T}$ cells results in $\mathrm{T}$ cell activation, proliferation, and production of IFN- $\gamma$ and TNF- $\alpha$, which in turn supports foam cell formation by promoting uptake oxLDL and mmLDL by macrophages. This mechanism is a likely link by which adaptive immunity promotes atherosclerosis.

\section{Methods}

Mice. B6, OTII, and Apoe $e^{-/-}$mice were obtained from Jackson Labs. Cd11c$\mathrm{YFP}^{+}$mice (58) were provided by M. Nussenzweig (Rockefeller University, New York, New York, USA). SMARTA transgenic mice were provided by M. von Herrath (LIAI, La Jolla, California, USA). All mice were on C57BL/6 background. Beginning at 8 weeks of age, female and male $A p o e^{-/-}$and B6 mice were fed WD. After 12 weeks of WD feeding, WD-fed Apoe $e^{-/}$and B6 mice and age-matched Apoe ${ }^{-/-}$and B6 mice fed chow diet (CD) were used for flow cytometry. CD11c-YFP ${ }^{+} \mathrm{B} 6$ mice were used for 2-photon microscopy at 8-12 weeks of age. Apoe ${ }^{-/-}$CD $11 c-Y F P^{+}$mice were fed WD for 12 or 20 weeks beginning at 8 weeks of age. Mice were kept in specific pathogen-free conditions in an AAALAC-approved barrier facility. All mice were genotyped using standard PCR protocols.

Aortic single-cell preparations and flow cytometry analysis. Preparation of single-cell suspensions from aortas was done as described previously (55), with some modifications. Briefly, mice were sacrificed by $\mathrm{CO}_{2}$, and aortas were perfused with PBS containing heparin $(20 \mathrm{U} / \mathrm{ml})$. Aortas were prepared by removal of all adventitial fat, cut into small pieces, and incubated for 50 minutes at $37^{\circ} \mathrm{C}$ with gentle shaking in a mixture of $450 \mathrm{U} / \mathrm{ml} \mathrm{col-}$ lagenase type I, $250 \mathrm{U} / \mathrm{ml}$ collagenase type XI, $120 \mathrm{U} / \mathrm{ml}$ hyaluronidase, and $120 \mathrm{U} / \mathrm{ml}$ DNAseI (all enzymes from Sigma-Aldrich).

To separate the adventitia from the rest of the vessel, we used a previously described method (32), with some modifications. Briefly, aortas were digested with $210 \mathrm{U} / \mathrm{ml}$ collagenase II and $3.75 \mathrm{U} / \mathrm{ml}$ elastase
(Worthington Biochemical Corp.) for 30 minutes at $37^{\circ} \mathrm{C}$, and the adventitia was carefully removed. Aortas and adventitias were further digested separately for an additional 30 minutes at $37^{\circ} \mathrm{C}$ with the standard digestion mixture described above $(450 \mathrm{U} / \mathrm{ml}$ collagenase type I, $250 \mathrm{U} / \mathrm{ml}$ collagenase type XI, $120 \mathrm{U} / \mathrm{ml}$ hyaluronidase, and $120 \mathrm{U} / \mathrm{ml}$ DNAseI; all enzymes from Sigma-Aldrich). Cell suspensions were filtered through 70- $\mu \mathrm{m}$ cell strainers and stained with CD45-PerCP (30-F11; BD Biosciences), CD11b-eFluor 450 (M1/70; eBioscience), CD11c-allophycocyanin (N418; eBioscience), MHCII-Alexa Fluor 700 (M5/114.15.2; eBioscience), TCRß-AF700 (H57-597; BioLegend), F4/80-Cy7PE (BM8; BioLegend), Ly6G (IA8; BioLegend), CD205 (DEC205) (NLDC-145; BioLegend), and Aqua LIVE/DEAD Fixable Dead cell staining Kit (Invitrogen) for flow cytometry (LSRII; BD). Live CD $45^{+}$cells were analyzed using FlowJo software (Tree Star Inc.). For detection of proliferating cells, B6 and 21-weekold Apoe $e^{-/-}$mice ( 15 weeks WD) received $1 \mathrm{mg} \mathrm{BrdU}$ in $200 \mu \mathrm{l} \mathrm{PBS}$ i.p. at 0 and 12 hours, and aortas were collected at 24 hours. Incorporation of BrdU was measured by flow cytometry using anti-BrdU-FITC antibody staining (BD Biosciences - Pharmingen) according to the manufacturer's protocol and analyzed by flow cytometry.

Histology and immunofluorescence. For histological analysis, aortic roots were frozen in OCT compound on dry ice and stored at $-80^{\circ} \mathrm{C}$. $5-\mu \mathrm{m} \mathrm{sec}-$ tions were taken in the aortic valve plane, and immunostaining was performed as described previously (80). Briefly, frozen sections were thawed and fixed for 10 minutes in acetone at room temperature, followed by 8 minutes in $1 \%$ paraformaldehyde (EMS) in $100 \mathrm{mM}$ dibasic sodium phosphate containing $60 \mathrm{mM}$ lysine and $7 \mathrm{mM}$ sodium periodate at $\mathrm{pH}$ 7.4 on ice. Sections were blocked using the avidin/biotin blocking kit (Vector Labs) followed by $5 \%$ normal goat serum (Caltag Laboratories) and 1\% BSA (Sigma-Aldrich) in PBS. Sections were stained overnight at room temperature with rat anti-mouse CD11b-FITC (M1/70; BD Biosciences) and hamster anti-CD11c (BD Bioscience) followed by staining with secondary antibody: anti-FITC Alexa Fluor 488 (Molecular Probes) and DyLight 649-labeled goat anti-hamster IgG (Jackson Immunoresearch). Images were acquired on a Leica DM6000 upright microscope using HCX PLAPO $\times 20$ and $\times 40$ oil-immersion objectives at 488 -nm and $633-\mathrm{nm}$ excitation wavelengths. NIH ImageJ was used to adjust brightness and 1-step smoothing on all images in parallel.

Cell sorting and labeling and antigen presentation in explanted aorta. Lymphocytes were harvested from spleen and lymph nodes, and $\mathrm{CD} 4{ }^{+} \mathrm{T}$ cells were purified by Robosep negative selection (StemCell Technology). After 48 hours of prestimulation with anti-CD3 and anti-CD28 antibodies, OTII or SMARTA CD $4^{+} \mathrm{T}$ cells were labeled with $2.5 \mu \mathrm{M}$ SNARF (red fluorescent carboxylic acid, acetate, succinimidyl ester) or $3 \mu \mathrm{M}$ CMRA (CellTracker Orange), respectively (Molecular Probes), for 10 minutes at $37^{\circ} \mathrm{C}$. CD4 ${ }^{+}$ $\mathrm{T}$ cells obtained from WD-fed Apoe $\mathrm{C}^{-/}$mice were used without additional stimulation. $\mathrm{CD} 4^{+} \mathrm{T}$ cells were resuspended at $1.5 \times 10^{6} \mathrm{cells} / \mathrm{ml}$. The arch, the thoracic aorta, and part of the abdominal aorta (above the renal arteries) were surgically removed. All paraaortic lymph nodes and adipose tissue were carefully removed without disturbing the aortic wall itself. T cells were incubated with the explanted aorta for 12 hours in complete RPMI 1640 media containing 10\% FBS, penicillin/streptomycin, L-glutamine, NEAA, HEPES, and sodium pyruvate in the presence or absence of antigenic peptide (OVA ${ }^{323-339}, 1 \mu \mathrm{M}$; Abgent) or OVA $(1 \mathrm{mg} / \mathrm{ml})$. Immediately preceding video acquisition, the ends of each aorta were glued to a coverslip with Histoacryl glue (TissueSeal), put in a Petri dish, maintained at $37^{\circ} \mathrm{C}$, and superfused with RPMI medium 1640 without phenol red (Invitrogen) bubbled with a gas mixture containing $95 \% \mathrm{O}_{2}$ and $5 \% \mathrm{CO}_{2}$.

Cytometric bead array. Explanted aortas were incubated for 48 hours with OTII T cells sorted as described above and stimulated for 8 hours with antiCD3 and anti-CD28 antibodies in complete RPMI 1640 media containing 
10\% FBS, penicillin/streptomycin, L-glutamine, NEAA, HEPES, and sodium pyruvate in the presence or absence of OVA ${ }^{323-339}$ (Abgent). Other explanted aortas were incubated for 12 hours without additional antigens with either $\mathrm{CD} 44^{\mathrm{lo}} \mathrm{CD} 62 \mathrm{~L}^{+}$naive or $\mathrm{CD} 44^{\text {hi }} \mathrm{CD} 62 \mathrm{~L}^{-}$activated effector-memory $\mathrm{CD} 25$ $\mathrm{CD}^{+} \mathrm{T}$ cells from Apoe er- $^{-/}$mice fed WD for 12 weeks. Supernatants were collected, and cytokine secretion was measured by mouse Th1/Th2/Th17 cytometric bead array (BD Biosciences). Secretion of TNF- $\alpha$, IFN- $\gamma$, and IL-4 was measured according to the manufacturer's instructions.

LDL uptake and foam cell formation. To assay LDL uptake in explanted aortas, aortas were isolated from 12-week-old CD45.1 Apoe - $^{-}$mice fed CD. Aortas were cocultured for 48 hours with OTII prestimulated for 8 hours with anti-CD3 and anti-CD28. During the last 18 hours, $2.5 \mu \mathrm{g} / \mathrm{ml}$ Dil-oxLDL (Biomedical Tech Inc.) or $2.5 \mu \mathrm{g} / \mathrm{ml}$ AF633-mmLDL was added to assay its uptake and foam cell formation. LDL was isolated from plasma of normolipidemic donors by sequential ultracentrifugation (81). Modified LDL preparations were tested for possible endotoxin contamination using a LAL kit (Cambrex). Only LDL preparations with LPS content less than $50 \mathrm{pg} / \mathrm{mg}$ protein were used in experiments. To produce AF633-mmLDL, $50 \mu \mathrm{g} / \mathrm{ml}$ of AF633-nLDL was incubated in serum-free DMEM for 18 hours with murine fibroblast cells overexpressing human 15-lipoxygenase, as reported previously (62). The mmLDL modification was tested in an in vitro biological assay in which AF633-mmLDL was examined for the induction of spreading and macropinocytosis in J774 macrophages (62).

Cell sorting of naive and activated $T$ cells. For CD25-CD4+ $\mathrm{T}$ cell isolation, spleens and lymph nodes were removed from B6 or $\mathrm{Apoe}^{-/-}$mice after 12 weeks of WD feeding, teased into single-cell suspensions, and filtered through a 70- $\mu \mathrm{m}$ cell strainer (Fisher Scientific). CD25-CD4+ $\mathrm{T}$ cells were isolated by Robosep negative selection kit (StemCell Technology). CD4 ${ }^{+} \mathrm{T}$ cells were stained with anti-CD25-allophycocyanin (PC61.5), anti-CD4-PE (GK1.5), anti-CD62L-Cy7PE (MEL-14), and anti-CD44-Pacific Blue (IM7; eBioscience). The $\mathrm{CD} 4{ }^{\mathrm{hi}} \mathrm{CD} 25^{-} \mathrm{CD} 44^{\mathrm{lo}} \mathrm{CD} 62 \mathrm{~L}^{+}$(naive) and $\mathrm{CD} 44^{\mathrm{hi}} \mathrm{CD} 62 \mathrm{~L}^{-}$ (activated) $\mathrm{T}$ cell populations were sorted by flow cytometry using a FACS Aria II cell sorter ( $>99 \%$ purity). Either naive or activated T cells were incubated with aortas from Apoe-/- mice for 12 hours followed by 2-photon microscopy imaging.

Bone marrow transplantation and depletion of DCs. Recipient mice (Apoe $\left.{ }^{-/}\right)$ were irradiated in 2 doses of 5.5 Gy each (for a total 11 Gy) 3 hours apart. Femurs and tibias of donor mice $\left(A p o e^{-/-} C d 11 c-D T R^{+}\right)$were collected, and bone marrow cells were isolated under sterile conditions. Bone marrow cells were resuspended in sterile PBS, and $300 \mu \mathrm{l}$ of cell suspension containing $5 \times 10^{6}$ cells was retro-orbitally injected i.v. into recipient mice. After transplantation, recipient mice were provided with autoclaved food and autoclaved acidified water containing antibiotic (trimethoprim-sulfamethoxazoline). To assay the role of DC depletion in atherosclerosis, Apoe $e^{-/-C d 11 c-D T R^{+}}$ mice were injected with DT ( $8 \mu \mathrm{g} / \mathrm{g}$ body weight) every other day for 2 weeks.

To assay oxLDL uptake, Apoe ${ }^{-/-C} d 11 c-D T R^{+}$mice were injected with DT ( $8 \mu \mathrm{g} / \mathrm{g}$ body weight). 24 hours later, aortas were harvested and incubated with prestimulated OTII T cells in the presence of OVA. oxLDL uptake was measured as described above.

Gene expression. For gene expression analysis, aortas were isolated and snap-frozen in liquid nitrogen. Aortas were homogenized in RLT buffer (Qiagen) and frozen at $-80^{\circ} \mathrm{C}$. Total RNA was isolated using the RNA easy RNA purification system (Qiagen) and treated with DNase I (Promega) before first strand cDNA synthesis using the Superscript II system, according to the random priming protocol (Invitrogen). Gene expression was analyzed by SybrGreen real-time PCR using primers for actin, L32, Il6, and Il12p35. Primer sequences were obtained from NIH QPrimerDepot (http://mouseprimerdepot.nci.nih.gov). Reactions were performed in triplicate for each gene, and gene expression was normalized to $\beta$-actin and L32 housekeeping gene expression. 2-photon microscopy. 2-photon imaging was performed using a DM 6000 upright microscope with 4 nondescanned detectors (Leica Microsystems) and a Chameleon Ultra Ti: Sapphire laser (Coherent) tuned at 900-1,000 nm for acquisition using a water-dipping objective (Olympus XLUMPLFL 20XW, NA0.95). Emitted fluorescence was split with 2 dichroic mirrors $(560 \mathrm{~nm}$ and $593 \mathrm{~nm}$ ) and passed through filters (Semrock) at 535/22 nm, $585 / 40 \mathrm{~nm}$, and $624 / 40 \mathrm{~nm}$. Typically, $10-20 z$ planes spaced $10-15 \mu \mathrm{m}$ apart were acquired at $512 \times 512$ pixels every 1 minute.

Image processing. Images were smoothed by median filtering at kernel size $3 \times 3$ pixels. 3D reconstructions of aortas were performed using Imaris software (version 7.1.1 $\times 64$; Bitplane AG) after stitching several $z$ series encompassing the artery using XuvTools software (82). Aortic walls were visualized by second harmonic generation and autofluorescence signals. Autofluorescence was recorded as a separate channel (emission range above $560 \mathrm{~nm}$ with 920-950 nm excitation) or was extracted as low-intensity pixels from YFP, CMRA, or SNARF channels, which were then combined and converted to a new channel. Modeling of T cell-DC interactions in 3D was done using Imaris software.

Cell tracking. Each video was registered in $x, y$, and $z$ using a vector field convolution on the $2 \mathrm{D}$ projections in the $x y$ dimension of the cells (83). The shape of the DC was computed using an active contour guided by vector field convolution (83) on the $2 \mathrm{D}$ projections in the $x y$ dimension of the cells. Commencing with a binary $2 \mathrm{D}$ image of the detected DC, an edge map was created. Then, a user-defined vector field kernel was convolved with the edge map. This convolution produced a field of vectors that served as forces to guide the active contours to the cell boundaries. With this field, an initialized contour was deformed iteratively on the image until the desired features were captured. For each frame of the video, 3D size and shape features were extracted from the cells that were detected. The detections were assembled over time into tracks via a multitarget tracker that uses nearest-neighbor data association and a Kalman filter. The green and red cell tracks were subsequently postprocessed to determine interaction duration, feature changes, and cell velocities.

Imaris software was also used to automatically process $3 \mathrm{D}$ video data by detecting cells in each fluorescence channel, then creating tracks by linking the detected cells over time. Tracks were manually edited to improve accuracy. The software calculated interaction duration and cell velocities.

Statistics. Student's 2-tailed $t$ test and ANOVA were used to compare treated and untreated conditions. Data are expressed as mean \pm SEM. $P$ values less than 0.05 were considered significant.

Study approval. Animal experiments were approved by the Animal Care Committee at LIAI.

\section{Acknowledgments}

The authors thank Hui Ouyang for expert animal husbandry and technical assistance; Olga Turovskaya and Keely Arbenz-Smith for expert help with histology; Goran Hansson and Sergei Grivennikov for critical reading of the manuscript and helpful suggestions; and Iftach Shaked for helpful suggestions. This work was supported by NIH grant HL58108 to K. Ley, American Heart Association Fellowship no. 10POST4160142-01 to E.K. Koltsova, and a Deutsche Forschungsgemeinschaft grant to S. von Vietinghoff.

Received for publication November 2, 2011, and accepted in revised form June 21, 2012.

Address correspondence to: Klaus Ley, Division of Inflammation Biology, La Jolla Institute for Allergy and Immunology, 9420 Athena Circle, La Jolla, California 92037, USA. Phone: 858.752.6500; Fax: 858.752.6985; E-mail: Klaus@liai.org. 
1. Weber C, Zernecke A, Libby P. The multifaceted contributions of leukocyte subsets to atherosclerosis: lessons from mouse models. Nat Rev Immunol. 2008;8(10):802-815.

2. Andersson J, Libby P, Hansson GK. Adaptive immunity and atherosclerosis. Clin Immunol. 2010; 134(1):33-46.

3. Galkina E, Ley K. Immune and inflammatory mechanisms of atherosclerosis. Annu Rev Immunol. 2009;27:165-197.

4. Stoneman V, et al. Monocyte/macrophage suppression in CD11b diphtheria toxin receptor transgenic mice differentially affects atherogenesis and established plaques. Circ Res. 2007;100(6):884-893.

5. Mantovani A, Garlanda C, Locati M. Macrophage diversity and polarization in atherosclerosis: a question of balance. Arterioscler Thromb Vasc Biol. 2009; 29(10):1419-1423.

6. Soehnlein O, Weber C. Myeloid cells in atherosclerosis: initiators and decision shapers. Semin Immunopathol. 2009;31(1):35-47.

7. Ley K, Miller YI, Hedrick CC. Monocyte and macrophage dynamics during atherogenesis. Arterioscler Thromb Vasc Biol. 2011;31(7):1506-1516.

8. Gerrity RG. The role of the monocyte in atherogenesis: I. Transition of blood-borne monocytes into foam cells in fatty lesions. Am J Pathol. 1981; 103(2):181-190.

9. Gerrity RG. The role of the monocyte in atherogenesis: II. Migration of foam cells from atherosclerotic lesions. Am J Pathol. 1981;103(2):191-200.

10. Iwasaki A, Medzhitov R. Toll-like receptor control of the adaptive immune responses. Nat Immunol. 2004;5(10):987-995.

11. Kleemann R, Zadelaar S, Kooistra T. Cytokines and atherosclerosis: a comprehensive review of studies in mice. Cardiovasc Res. 2008;79(3):360-376.

12. Lundberg AM, Hansson GK. Innate immune signals in atherosclerosis. Clin Immunol. 2010; 134(1):5-24.

13. Bobryshev YV, Lord RS. Ultrastructural recognition of cells with dendritic cell morphology in human aortic intima. Contacting interactions of Vascular Dendritic Cells in athero-resistant and athero-prone areas of the normal aorta. Arch Histol Cytol. 1995;58(3):307-322.

14. Choi JH, et al. Identification of antigen-presenting dendritic cells in mouse aorta and cardiac valves. J Exp Med. 2009;206(3):497-505.

15. Paulson KE, Zhu SN, Chen M, Nurmohamed S, Jongstra-Bilen J, Cybulsky MI. Resident intimal dendritic cells accumulate lipid and contribute to the initiation of atherosclerosis. Circ Res. 2010; 106(2):383-390.

16. Han JW, et al. Vessel wall-embedded dendritic cells induce T-cell autoreactivity and initiate vascular inflammation. Circ Res. 2008;102(5):546-553.

17. Choi JH, et al. Flt3 signaling-dependent dendritic cells protect against atherosclerosis. Immunity. 2011;35(5):819-831.

18. Weber C, et al. CCL17-expressing dendritic cells drive atherosclerosis by restraining regulatory $\mathrm{T}$ cell homeostasis in mice. $J$ Clin Invest. 2011; 121(7):2898-2910.

19. Angeli V, et al. Dyslipidemia associated with atherosclerotic disease systemically alters dendritic cell mobilization. Immunity. 2004;21(4):561-574.

20. Miller MJ, Wei SH, Parker I, Cahalan MD. Twophoton imaging of lymphocyte motility and antigen response in intact lymph node. Science. 2002; 296(5574):1869-1873.

21. Mempel TR, Henrickson SE, Von Andrian UH. $\mathrm{T}$-cell priming by dendritic cells in lymph nodes occurs in three distinct phases. Nature. 2004; 427(6970):154-159.

22. Filipe-Santos $\mathrm{O}$, et al. A dynamic map of antigen recognition by CD4 $\mathrm{T}$ cells at the site of Leishmania major infection. Cell Host Microbe. 2009;6(1):23-33.
23. Egen JG, Rothfuchs AG, Feng CG, Horwitz MA, Sher A, Germain RN. Intravital imaging reveals limited antigen presentation and $\mathrm{T}$ cell effector function in mycobacterial granulomas. Immunity. 2011;34(5):807-819.

24. Kawakami N, Nagerl UV, Odoardi F, Bonhoeffer T, Wekerle H, Flugel A. Live imaging of effector cell trafficking and autoantigen recognition within the unfolding autoimmune encephalomyelitis lesion. J Exp Med. 2005;201(11):1805-1814.

25. Mallat Z, Taleb S, Ait-Oufella H, Tedgui A. The role of adaptive $\mathrm{T}$ cell immunity in atherosclerosis. J Lipid Res. 2009;50(suppl):S364-S369.

26. Kolbus D, et al. CD8+ T cell activation predominate early immune responses to hypercholesterolemia in Apoe(/) mice. BMC Immunol. 2010;11:58.

27. Dansky HM, Charlton SA, Harper MM, Smith JD. $\mathrm{T}$ and $\mathrm{B}$ lymphocytes play a minor role in atherosclerotic plaque formation in the apolipoprotein E-deficient mouse. Proc Natl Acad Sci U S A. 1997; 94(9):4642-4646.

28. Schulte S, Sukhova GK, Libby P. Genetically programmed biases in Th1 and Th2 immune responses modulate atherogenesis. Am J Pathol. 2008; 172(6):1500-1508.

29. Buono C, Binder CJ, Stavrakis G, Witztum JL, Glimcher LH, Lichtman AH. T-bet deficiency reduces atherosclerosis and alters plaque antigenspecific immune responses. Proc Natl Acad SciUS A. 2005;102(5):1596-1601

30. Tellides G, et al. Interferon-gamma elicits arteriosclerosis in the absence of leukocytes. Nature. 2000;403(6766):207-211

31. van Es T, et al. Attenuated atherosclerosis upon IL-17R signaling disruption in LDLr deficient mice. Biochem Biophys Res Commun. 2009;388(2):261-265.

32. Smith E, et al. Blockade of interleukin-17A results in reduced atherosclerosis in apolipoprotein E-deficient mice. Circulation. 2010;121(15):1746-1755.

33. Chen S, Shimada K, Zhang W, Huang G, Crother TR, Arditi M. IL-17A is proatherogenic in high-fat diet-induced and Chlamydia pneumoniae infection-accelerated atherosclerosis in mice. J Immunol. 2010;185(9):5619-5627.

34. Gao Q, et al. A critical function of Th17 proinflammatory cells in the development of atherosclerotic plaque in mice. IImmunol. 2010;185(10):5820-5827.

35. Erbel C, et al. Inhibition of IL-17A attenuates atherosclerotic lesion development in apoE-deficient mice. J Immunol. 2009;183(12):8167-8175.

36. Butcher MJ, Gjurich BN, Phillips T, Galkina EV. The IL-17A/IL-17RA axis plays a proatherogenic role via the regulation of aortic myeloid cell recruitment. Circ Res. 2012;110(5):675-687.

37. Usui $F$, et al. Interleukin-17 deficiency reduced vascular inflammation and development of atherosclerosis in Western diet-induced apoE-deficient mice. Biochem Biophys Res Commun. 2012;420(1):72-77.

38. Taleb S, et al. Loss of SOCS3 expression in T cells reveals a regulatory role for interleukin-17 in atherosclerosis. J Exp Med. 2009;206(10):2067-2077.

39. Madhur MS, et al. Role of interleukin 17 in inflammation, atherosclerosis, and vascular function in apolipoprotein e-deficient mice. Arterioscler Thromb Vasc Biol. 2011;31(7):1565-1572.

40. Danzaki K, et al. Interleukin-17A deficiency accelerates unstable atherosclerotic plaque formation in apolipoprotein E-deficient mice. Arterioscler Thromb Vasc Biol. 2012;32(2):273-280.

41. Mor A, et al. Role of naturally occurring CD4+ $\mathrm{CD} 25+$ regulatory $\mathrm{T}$ cells in experimental atherosclerosis. Arterioscler Thromb Vasc Biol. 2007; 27(4):893-900

42. Ait-Oufella H, et al. Natural regulatory T cells control the development of atherosclerosis in mice. Nat Med. 2006;12(2):178-180.

43. Xie JJ, et al. The Th17/Treg functional imbalance during atherogenesis in ApoE(-/-) mice. Cytokine.
2009;49(2):185-193

44. Palinski W, et al. Cloning of monoclonal autoantibodies to epitopes of oxidized lipoproteins from apolipoprotein E-deficient mice. Demonstration of epitopes of oxidized low density lipoprotein in human plasma. J Clin Invest. 1996;98(3):800-814.

45. Wick G, Knoflach M, Xu Q. Autoimmune and inflammatory mechanisms in atherosclerosis. Annu Rev Immunol. 2004;22:361-403.

46. Hansson GK, Hermansson A. The immune system in atherosclerosis. Nat Immunol. 2011;12(3):204-212.

47. Hermansson $A$, et al. Inhibition of $\mathrm{T}$ cell response to native low-density lipoprotein reduces atherosclerosis. J Exp Med. 2010;207(5):1081-1093.

48. Buono C, Pang H, Uchida Y, Libby P, Sharpe AH, Lichtman AH. B7-1/B7-2 costimulation regulates plaque antigen-specific T-cell responses and atherogenesis in low-density lipoprotein receptor-deficient mice. Circulation. 2004;109(16):2009-2015.

49. Faure-Andre G, et al. Regulation of dendritic cell migration by CD74, the MHC class II-associated invariant chain. Science. 2008;322(5908):1705-1710.

50. Sun J, et al. Deficiency of antigen-presenting cell invariant chain reduces atherosclerosis in mice. Circulation. 2010;122(8):808-820.

51. Erbel C, et al. Functional profile of activated dendritic cells in unstable atherosclerotic plaque. Basic Res Cardiol. 2007;102(2):123-132.

52. van Zandvoort M, et al. Two-photon microscopy for imaging of the (atherosclerotic) vascular wall: a proof of concept study. J Vasc Res. 2004;41(1):54-63.

53. Boulesteix T, et al. Micrometer scale ex vivo multiphoton imaging of unstained arterial wall structure. Cytometry A. 2006;69(1):20-26.

54. Maffia P, et al. Images in cardiovascular medicine. Multiphoton microscopy for 3-dimensional imaging of lymphocyte recruitment into apolipoprotein-E-deficient mouse carotid artery. Circulation. 2007;115(11):e326-e328.

55. Galkina E, Kadl A, Sanders J, Varughese D, Sarembock IJ, Ley K. Lymphocyte recruitment into the aortic wall before and during development of atherosclerosis is partially L-selectin dependent. J Exp Med. 2006;203(5):1273-1282.

56. Wu H, et al. Functional role of CD11 + monocytes in atherogenesis associated with hypercholesterolemia. Circulation. 2009;119(20):2708-2717.

57. Hashimoto D, Miller J, Merad M. Dendritic cell and macrophage heterogeneity in vivo. Immunity. 2011;35(3):323-335

58. Lindquist RL, et al. Visualizing dendritic cell networks in vivo. Nat Immunol. 2004;5(12):1243-1250.

59. Oxenius A, Bachmann MF, Zinkernagel RM, Hengartner H. Virus-specific MHC-class II-restricted TCR-transgenic mice: effects on humoral and cellular immune responses after viral infection. Eur J Immunol. 1998;28(1):390-400.

60. Schett $\mathrm{G}$, et al. Autoantibodies against heat shock protein 60 mediate endothelial cytotoxicity. J Clin Invest. 1995;96(6):2569-2577.

61. Steinman RM, Hemmi H. Dendritic cells: translating innate to adaptive immunity. Curr Top Microbiol Immunol. 2006;311:17-58.

62. Choi SH, et al. Lipoprotein accumulation in macrophages via toll-like receptor-4-dependent fluid phase uptake. Circ Res. 2009;104(12):1355-1363.

63. Anzinger JJ, et al. Native low-density lipoprotein uptake by macrophage colony-stimulating factordifferentiated human macrophages is mediated by macropinocytosis and micropinocytosis. Arterioscler Thromb Vasc Biol. 2010;30(10):2022-2031.

64. Zaft T, Sapoznikov A, Krauthgamer R, Littman DR, Jung S. CD11chigh dendritic cell ablation impairs lymphopenia-driven proliferation of naive and memory CD8+ T cells. J Immunol. 2005; 175(10):6428-6435

65. Bar-On L, Jung S. Defining in vivo dendritic cell functions using CD11c-DTR transgenic mice. 
Methods Mol Biol. 2010;595:429-442.

66. Hansson GK, Libby P. The immune response in atherosclerosis: a double-edged sword. Nat Rev Immunol. 2006;6(7):508-519.

67. Xu Q, et al. Serum soluble heat shock protein 60 is elevated in subjects with atherosclerosis in a general population. Circulation. 2000;102(1):14-20.

68. Combadiere C, et al. Decreased atherosclerotic lesion formation in CX3CR1/apolipoprotein E double knockout mice. Circulation. 2003;107(7):1009-1016.

69. Liu P, et al. CX3CR1 deficiency impairs dendritic cell accumulation in arterial intima and reduces atherosclerotic burden. Arterioscler Thromb Vasc Biol. 2008;28(2):243-250.

70. Combadiere C, et al. Combined inhibition of CCL2, CX3CR1, and CCR5 abrogates Ly6C(hi) and $\mathrm{Ly} 6 \mathrm{C}(\mathrm{lo})$ monocytosis and almost abolishes atherosclerosis in hypercholesterolemic mice. Circulation. 2008;117(13):1649-1657.

71. Gautier EL, et al. Conventional dendritic cells at the crossroads between immunity and cholesterol homeostasis in atherosclerosis. Circulation. 2009; 119(17):2367-2375.

72. Llodra J, Angeli V, Liu J, Trogan E, Fisher EA, Randolph GJ. Emigration of monocyte-derived cells from atherosclerotic lesions characterizes regressive, but not progressive, plaques. Proc Natl Acad Sci US A. 2004;101(32):11779-11784.

73. Grabner R, et al. Lymphotoxin beta receptor signaling promotes tertiary lymphoid organogenesis in the aorta adventitia of aged $\mathrm{ApoE}^{-/-}$mice. J Exp Med. 2009;206(1):233-248.

74. Ramos CL, et al. Direct demonstration of P-selectin- and VCAM-1-dependent mononuclear cell rolling in early atherosclerotic lesions of apolipoprotein E-deficient mice. Circ Res. 1999; 84(11):1237-1244.

75. Huo Y, Hafezi-Moghadam A, Ley K. Role of vascular cell adhesion molecule-1 and fibronectin connecting segment- 1 in monocyte rolling and adhesion on early atherosclerotic lesions. Circ Res. 2000;87(2):153-159.

76. Buono C, Come CE, Stavrakis G, Maguire GF, Connelly PW, Lichtman AH. Influence of interferon-gamma on the extent and phenotype of diet-induced atherosclerosis in the LDLR-deficient mouse. Arterioscler Thromb Vasc Biol. 2003; 23(3):454-460.

77. Gupta S, Pablo AM, Jiang X, Wang N, Tall AR, Schindler C. IFN-gamma potentiates athero- sclerosis in ApoE knock-out mice. J Clin Invest. 1997;99(11):2752-2761

78. Branen L, Hovgaard L, Nitulescu M, Bengtsson E, Nilsson J, Jovinge S. Inhibition of tumor necrosis factor-alpha reduces atherosclerosis in apolipoprotein E knockout mice. Arterioscler Thromb Vasc Biol. 2004;24(11):2137-2142.

79. Wuttge DM, et al. CXCL16/SR-PSOX is an interferon-gamma-regulated chemokine and scavenger receptor expressed in atherosclerotic lesions. Arterioscler Thromb Vasc Biol. 2004;24(4):750-755.

80. Zellweger RM, Prestwood TR, Shresta S. Enhanced infection of liver sinusoidal endothelial cells in a mouse model of antibody-induced severe dengue disease. Cell Host Microbe. 2010;7(2):128-139.

81. Havel RJ, Eder HA, Bragdon JH. The distribution and chemical composition of ultracentrifugally separated lipoproteins in human serum. J Clin Invest. 1955;34(9):1345-1353.

82. Emmenlauer M, et al. XuvTools: free, fast and reliable stitching of large 3D datasets. J Microsc. 2009; 233(1):42-60.

83. Li B, Acton ST. Active contour external force using vector field convolution for image segmentation. IEEE Trans Image Process. 2007;16(8):2096-2106. 